\title{
Transcriptional down-regulation of metabolic genes by Gdown1 ablation induces quiescent cell re-entry into the cell cycle
}

\author{
Miki Jishage, ${ }^{1}$ Keiichi Ito, ${ }^{1}$ Chi-Shuen Chu, ${ }^{1}$ Xiaoling Wang, ${ }^{1}$ Masashi Yamaji, ${ }^{2,3,4}$ \\ and Robert G. Roeder ${ }^{1}$ \\ ${ }^{1}$ Laboratory of Biochemistry and Molecular Biology, The Rockefeller University, New York, New York 10065, USA; ${ }^{2}$ Division of \\ Reproductive Sciences, ${ }^{3}$ Division of Human Genetics, Cincinnati Children's Hospital Medical Center, Cincinnati, Ohio, 45229, \\ USA; ${ }^{4}$ Department of Pediatrics, University of Cincinnati College of Medicine, Cincinnati, Ohio, 49267, USA
}

Liver regeneration and metabolism are highly interconnected. Here, we show that hepatocyte-specific ablation of RNA polymerase II (Pol II)-associated Gdown1 leads to down-regulation of highly expressed genes involved in plasma protein synthesis and metabolism, a concomitant cell cycle re-entry associated with induction of cell cyclerelated genes (including cyclin D1), and up-regulation of $p 21$ through activation of p53 signaling. In the absence of p53, Gdown1-deficient hepatocytes show a severe dysregulation of cell cycle progression, with incomplete mitoses, and a premalignant-like transformation. Mechanistically, Gdown1 is associated with elongating Pol II on the highly expressed genes and its ablation leads to reduced Pol II recruitment to these genes, suggesting that Pol II redistribution may facilitate hepatocyte re-entry into the cell cycle. These results establish an important physiological function for a Pol II regulatory factor (Gdown1) in the maintenance of normal liver cell transcription through constraints on cell cycle re-entry of quiescent hepatocytes.

[Keywords: cancer; cell cycle; metabolism; transcription regulation]

Supplemental material is available for this article.

Received February 18, 2020; revised version accepted April 14, 2020.

Hepatocytes are major players in carrying out liver functions, such as nutrient metabolism and synthesis of plasma proteins. Although they rarely divide, hepatocytes reenter the cell cycle upon liver injury or loss to restore liver mass (Michalopoulos 2017). For decades, the molecular mechanism of liver regeneration has been intensively studied to identify factors that regulate the regeneration, and these studies have unveiled signaling pathways associated with cytokines, growth factors, and transcription factors (Michalopoulos 2007). Although no studies have identified a single factor whose deletion abolishes liver regeneration (Michalopoulos 2014), a recent study showed that the combined elimination of receptor tyrosine kinases, MET, and epidermal growth factor receptor (EGFR) abolishes liver regeneration (Paranjpe et al. 2016). The study also showed that the elimination of MET and EGFR down-regulates genes involved in metabolic activities. In this regard, once quiescent cells commit to cell cycle entry, cellular metabolic activities must be changed in

Corresponding authors: roeder@mail.rockefeller.edu; jishagm@mail. rockefeller.edu

Article published online ahead of print. Article and publication date are online at http://www.genesdev.org/cgi/doi/10.1101/gad.337683.120. order to produce the components needed for cell doubling and cell survival. During liver regeneration, metabolic remodeling occurs along with cell division; and conversely, metabolic deficiency can impair regeneration (Huang and Rudnick 2014; Caldez et al. 2018). Therefore, liver regeneration and metabolism are interconnected.

Normal hepatocytes exhibit a liver-specific pattern of gene expression that is altered in response to conditions leading to liver regeneration and altered cell metabolism, and the gene expression programs are regulated at least in part at the level of transcription (Hirota and Fukamizu 2010; Kurinna and Barton 2011). The transcription of protein coding genes, as well as some genes producing snRNAs and microRNAs, is mediated by RNA polymerase II (Pol II) in association with a group of general initiation factors (TFIIA, TFIIB, TFIID, TFIIE, TFIIF, and TFIIH) that (with Pol II) form a preinitiation complex (PIC) at the promoter and by several elongation factors that facilitate

C 2020 Jishage et al. This article is distributed exclusively by Cold Spring Harbor Laboratory Press for the first six months after the full-issue publication date (see http://genesdev.cshlp.org/site/misc/terms.xhtml). After six months, it is available under a Creative Commons License (Attribution-NonCommercial 4.0 International), as described at http://creativecommons.org/licenses/by-nc/4.0/. 
promoter clearance and productive elongation (Roeder 2019|. The gene-selective formation and function of preinitiation complexes are in turn regulated by gene- and cell-specific enhancer-binding transcription factors that act through interactions with diverse transcriptional coactivators and corepressors. Foremost among the transcriptional coactivators is the large 30-subunit Mediator that is recruited by enhancer-bound transcription factors and, through Pol II interactions, facilitates enhancer-promoter interactions leading to PIC formation and function (Malik and Roeder 2010).

Pol II $(G)$ is a Pol II variant that contains the tightly associated Gdown 1 and comprises a minor subfraction of total Pol II. Gdown1 was originally recognized as one of the multiple polypeptides encoded in the GRINL1A region of the human genome (Roginski et al. 2004). It later was identified biochemically as a stoichiometric and tightly associated subunit (defined as the Pol II subunit POLR2M) of a fraction of total $\mathrm{Pol}$ II purified from liver ( $\mathrm{Hu}$ et al. 2006). Initial in vitro transcription assays reconstituted with purified Pol II and general initiation factors showed that Gdown1 inhibits transcription initiation but that Mediator can reverse this inhibition. Further biochemical and structural studies showed that Gdown1 blocks initiation by preventing interactions of initiation factors TFIIF and TFIIB with Pol II (Jishage et al. 2012, 2018), although the mechanism by which Mediator reverses Gdown1-mediated repression remains unclear. These results indicate a new mechanism of transcriptional regulation in which Gdown1 directly interacts with Pol II to restrict potentially inappropriate Pol II recruitment to promoter regions. However, there is little information regarding the biological functions of Pol II $(\mathrm{G})$ and how the clearly evident in vitro repressive function of Gdown1 relates to transcriptional regulation in vivo.

In this study, prompted in part by the original discovery of Pol II(G) in porcine liver (Hu et al. 2006), the inhibitory nature of Gdown1, and the quiescent state of hepatocytes, we analyzed the function of Gdown1 in liver by a genetic analysis. We show that Gdown1 ablation in hepatocytes causes a surprising down-regulation of highly expressed, Gdown1-associated genes involved in metabolic pathways and synthesis of plasma proteins in the liver, indicative of a direct positive role for Gdown1 in transcription, and that this triggers hepatocyte re-entry into the cell cycle. We also show that the joint ablation of Gdown1 and p53 leads to dysregulated cell cycle progression, thereby implicating metabolic reprogramming in the molecular mechanism of malignant transformation.

\section{Results}

Gdown1 is essential for mouse early embryonic development

As an initial approach to investigate the biological role of Gdown1, we generated mice (Gdown $1^{f / f}$; designated FF mice) carrying floxed exons in the Gdown1 locus, such that Cre-recombinase expression excises exons encoding domains critical for the transcriptional inhibitory activity of Gdown1 (Supplemental Fig. S1A; Jishage et al. 2018). First, we examined the effect of Gdown1 ablation in mouse embryo development. Mice carrying a Gdown1 knockout allele were generated by crossing Gdown $1^{f / f}$ mice with E2A-Cre transgenic mice (Materials and Methods). Gdown $1^{f /-}$ mice appeared normal and healthy. However, no Gdown $1^{-/-}$mice from intercrossing Gdown $1^{f /-}$ mice were obtained at postnatal day 21 (Supplemental Fig. S1B), indicating that Gdown1 knockout (KO) mice are embryonic lethal. Further analyses revealed that the number of Gdown $1^{-/}$embryos began to decrease at embryonic day 3.5 (E3.5) and that no nullizygous embryos were evident at E10.5 (Supplemental Fig. S1B). Since Gdown1 KO embryos were observed at E3.5, we generated embryonic stem cell (ESC) lines from Gdown $1^{f / f}(\mathrm{FF})$ mice carrying a tamoxifen-inducible Cre-ERT2 transgene in order to examine the impact of Gdown1 loss on ESCs. In a defined culture condition, >60 ESC clones were screened by a single colony culture to identify Gdown1 KO ESCs. However, the clones that survived after tamoxifen treatment were all heterozygous, suggesting that Gdown1 KO ESCs may die very quickly. Taken together, these results show that Gdown1 is critical for mouse early embryonic development.

\section{Loss of Gdown1 activates the p53 signaling pathway}

Because of the embryonic lethality, we next chose mouse liver to investigate the biological role of Gdown1. While ESCs divide every $24 \mathrm{~h}$, normal hepatocytes are quiescent and do not divide frequently (Taub 2004; Fausto et al. 2006; Michalopoulos 2007). We generated Gdown $1^{\text {flox/flox }}$ mice carrying an albumin(Alb)-Cre transgene (Gdown $1^{f / f ; A l b-C r e}$ mice; designated KO mice), and the hepatocyte-specific deletion of the Gdown 1 targeted allele was confirmed (Supplemental Fig. S1C). At 8 wk, Gdown1 protein expression in Gdown1 KO liver was barely detectable compared with expression of the Pol II RPB3 subunit (Supplemental Fig. S1D). In contrast to the observed lethal phenotype in Gdown1 KO embryos, KO mice displayed whole body and liver weights comparable with those of control (FF) mice (Supplemental Fig. S1E). However, liver function tests showed abnormal liver metabolic activities, such as elevated serum levels of alkaline phosphatase (ALP) and lowered serum levels of triglycerides (TRIG) (Fig. 1A), which suggested functional defects in KO liver. Histological analyses of KO liver showed further hepatocyte abnormalities such as large cells with enlarged nuclei (H\&E in Fig. 1B). Also, significant numbers of KO hepatocytes were Ki67-positive, which indicates that these cells had re-entered the cell cycle. While cell cycle re-entry was observed, a TUNEL assay detected a few apoptotic hepatocytes in Gdown1 KO liver (Fig. 1B). Although obvious necrotic lesions were not detected, the presence of apoptotic cells may explain the proliferation of SMA-positive cells associated with collagen deposition (Fig. 1B), whose emergence is often triggered by hepatic injury (Yin et al. 2013).

To understand the injury-like reactions, the transcriptome in Gdown1 KO liver was analyzed by microarrays. We identified 338 up-regulated genes and 246 down- 
A
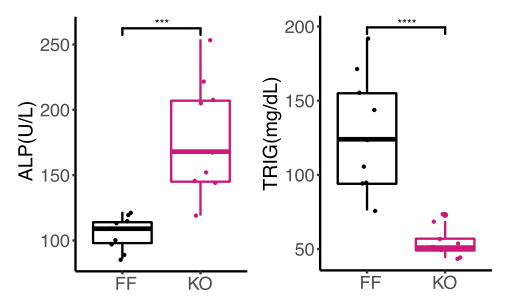

B
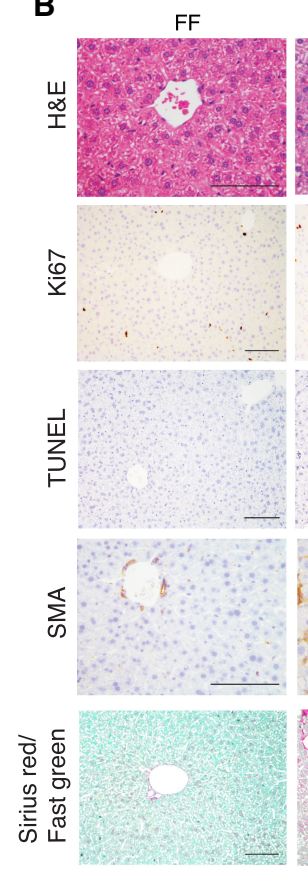

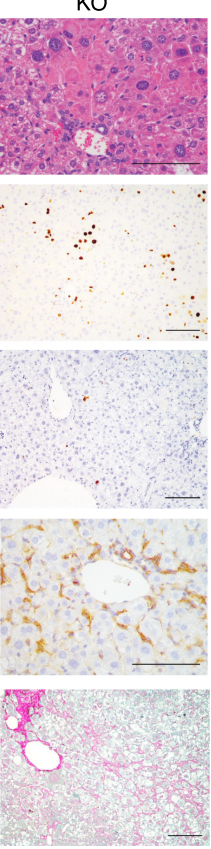

C

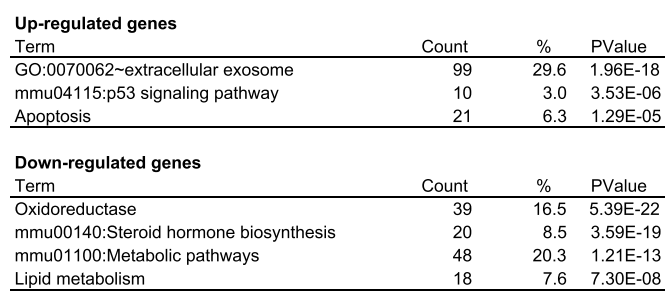

D

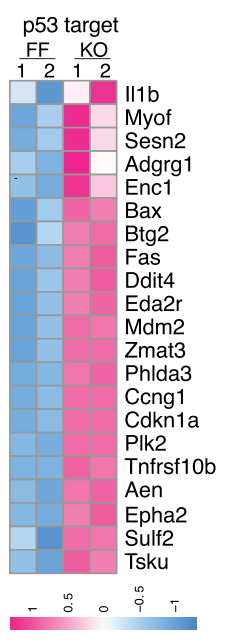

E

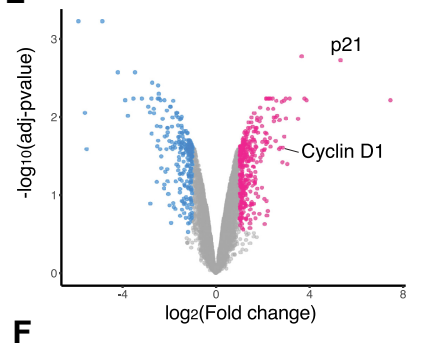

$\mathbf{F}$

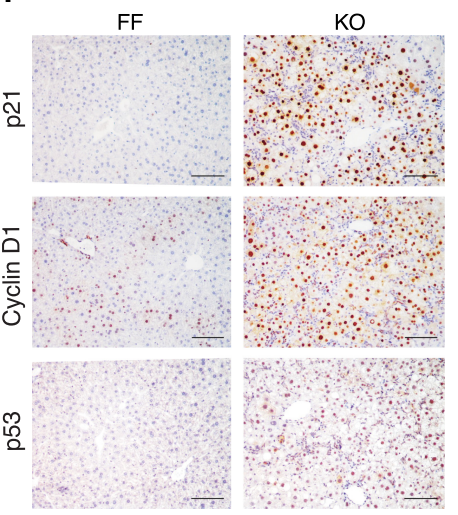

Figure 1. Loss of Gdown1 activates p53 signaling pathway. (A) Serum levels of alkaline phosphatase (ALP) and triglycerides (TRIG) in control (FF) and Gdown1 liver KO mice (KO). $\left(^{* * *}\right) P<0.001,\left({ }^{* * * *}\right) P<0.0001$ in unpaired two-tailed $t$-test. $(B)$ Representative liver histology in control (FF) and Gdown1 liver KO mice (KO). $(C)$ Gene ontology analysis for differentially expressed genes in Gdown1 KO liver. $(D)$ A heat map for p53 target genes that are up-regulated in Gdown1 KO liver. $(E)$ Volcano plot showing differentially expressed genes in Gdown1 KO liver. Deep pink or light blue color indicates significantly up-regulated or down-regulated genes, respectively (fold change $>2, P$ value $<0.05)$. (F) Representative liver histology in FF and Gdown1 KO mice. Scale bars, $100 \mu \mathrm{m}$.

regulated genes (fold change $>2, P$ value $<0.05$ ). GO analysis revealed that the up-regulated genes are significantly enriched in extracellular exosome, p53 signaling, and apoptosis pathways, whereas the down-regulated genes are highly involved in metabolic pathways that include xenobiotic metabolism and lipid metabolism (Fig. 1C). Among genes that are categorized as "extracellular exosome"and which also include genes localized in the plasma membrane, the Golgi apparatus, and the endoplasmic reticulum-we found several genes that are normally expressed in cholangiocytes (KRT19-positive cells) and that include Spp1, Epcam, and Prom1 (Supplemental Fig. S1F). Histological analyses confirmed the proliferation of cholangiocytes (Supplemental Fig. S1G), which is generally associated with biliary injury or exposure to alcohol, toxins or drugs (Alvaro et al. 2007). Although GO analysis identified only 10 genes involved in p53 signaling pathways (Fig. 1C), we found more genes that are direct targets of p53 (Fischer 2017), including proapoptotic genes such as Bax, Fas, and Tnfrsf10b (Fig. 1D). In particular, $C d k n 1 a / p 21$, which encodes the potent cell cycle inhibitor p21, was remarkably up-regulated (Fig. 1E). Also, beyond genes in p53 signaling pathways, we found that cyclin D1 was also significantly up-regulated (Fig. 1E). Histological analyses further confirmed expression at the protein level of cyclin D1, as well as p21 and p53, all of which were highly and uniformly expressed in KO liver (Fig. 1F). These results establish that Gdown1 KO in hepatocytes causes injury-like reactions that include cell death, cell cycle re-entry, and activation of p53 signaling pathways.

\section{Gdown1 KO hepatocytes re-enter the cell cycle}

To investigate how the Gdown1 KO elicits injury-like reactions, we monitored expression of $\mathrm{p} 21$ and cyclin D1 
proteins from 4- to 6-wk (W)-old KO livers. Cyclin D1 and p21 were both detected at $5 \mathrm{~W}$, when Gdown1 expression was nearly undetectable (Fig. 2A, lane 4) and further increased at $6 \mathrm{~W}$ (Fig. 2A, lane 6), indicating that activation of a p53 signaling pathway was initiated around $5 \mathrm{~W}$ of age. The number of Ki67-positive cells was elevated in $\mathrm{KO}$ liver at $5 \mathrm{~W}$, but followed by a decline at $6 \mathrm{~W}$ (Fig. 2B). The decreased number of Ki67-positive cells at $6 \mathrm{~W}$ was associated with $p 21$ induction accompanied by the expression of other p53 direct target genes that included Phlda3, Zmat3, and Eda2r (Supplemental Fig. S2), suggesting that the induced cell cycle re-entry and the subsequent progression was prevented through $p 21$ induction. Consistent with the observation of an increased number of Ki67-positive cells at 5W, Ser10 phosphorylated histone $\mathrm{H} 3$ also was detected at this stage (Fig. 2C), indicating that the cell cycle had progressed into the mitotic phase in some cells. Increases in both cyclin A2 and cyclin B2 RNA expression levels at $5 \mathrm{~W}$ further confirmed that the hepatocytes had re-entered the cell cycle at this stage (Fig. 2D). However, no obvious necrosis or SMA-positive myofibroblasts or apoptotic hepatocytes were detected at $5 \mathrm{~W}$ (Fig. 2E), suggesting that hepatic injury is unlikely to be the major cause of the cell cycle re-entry. Interestingly, expression of both cyclin D1 mRNA and protein was observed at $6 \mathrm{~W}$ (Fig. 2F), even though the cell cycle appeared to be arrested (Fig. 2B).

Taken together, these data suggest that Gdown1 KO causes cell cycle re-entry of hepatocytes in the absence of apparent hepatic injury or loss, but that an associated induction of $p 21$ leads to a subsequent cell cycle arrest.

\section{Gdown1 KO causes dysregulated cell cycle progression in the absence of $p 53$}

As discussed above, the cell cycle re-entry elicited by Gdown1 KO in hepatocytes appears to be reversed by p21 induction, and this appears to be mediated through p53 activation based on the concomitant induction of several known p53 target genes. Notably, Gdown1 KO hepatocytes were subject to apoptosis at $8 \mathrm{~W}$ under conditions where the induced $\mathrm{p} 21$ would be expected to act as an antiapoptotic factor. These results suggest that the actual Gdown1 KO impact on hepatocytes might be partly concealed by the action of the induced p53. To test this possibility, we generated Gdown $1^{f / f ; A l b-C r e}$ mice that also carry a $p 53$ null mutation (designated DKO mice). As expected, p21 induction was abolished in the DKO liver at 6W (Fig. 3A). Consequently, Ki67-positive DKO hepatocytes were observed at $6 \mathrm{~W}$, in contrast to what was observed in individual p53 KO or Gdown1 KO livers at 6W (Figs. 3B, 2B). These results indicate that the observed cell cycle re-entry at $5 \mathrm{~W}$ was subsequently countered by p53-induced p21. Moreover, TUNEL assays failed to detect any apoptotic cells (Fig. 3B), suggesting that this re-entry was not likely to be caused by compensatory proliferation.

At 8W, the number of Ki67-positive DKO hepatocytes was further increased (Fig. 3C). More interestingly, H\&E
A

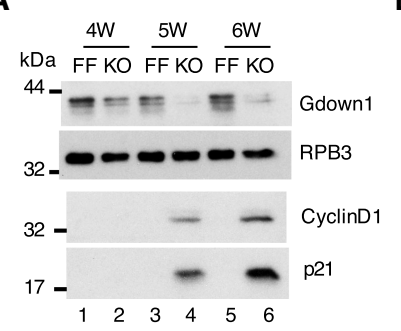

C
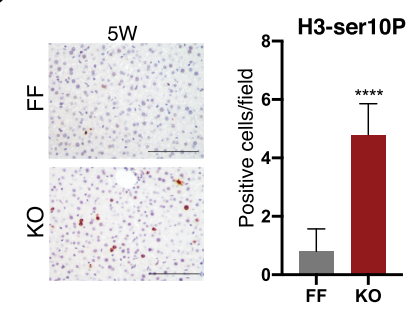

E

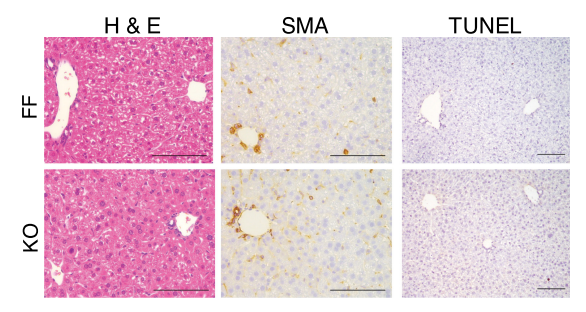

B
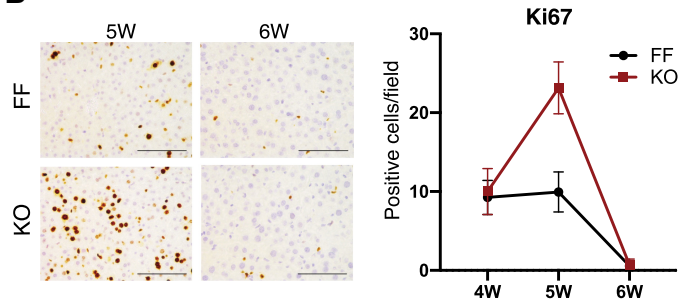

D Cyclin A2
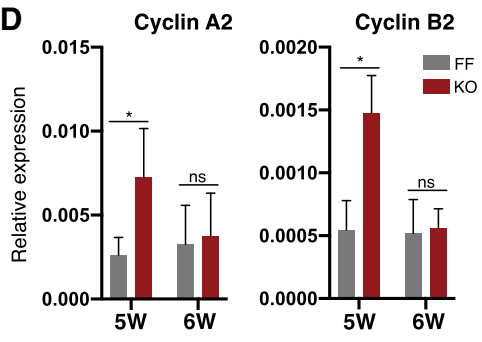

$\mathbf{F}$

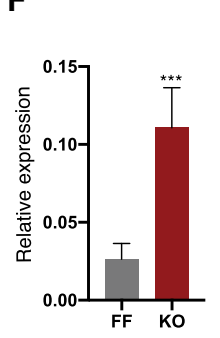

Figure 2. Gdown1 KO hepatocytes re-enter the cell cycle. (A) Protein expression in control (FF) or Gdown1 liver KO mice (KO) at the indicated ages in weeks (W). Liver whole-cell extracts were analyzed by immunoblot. RPB3 serves as a loading control. $(B$, left $)$ Representative liver histology for Ki67-positive hepatocytes in FF and $\mathrm{KO}$ mice at the indicated ages. Scale bars, $100 \mu \mathrm{m}$. (Right) Quantification of Ki67-positive cells at the indicated ages of weeks $(\mathrm{W})$. $(C$, left $)$ Representative liver histology for histone H3 Ser10 phosphorylated positive hepatocytes in FF and Gdown1 KO at 5W. Scale bars, $100 \mu \mathrm{m}$. (Right) Quantification of histone H3 Ser10 phosphorylated-positive cells at $5 \mathrm{~W} .\left(^{* * * *}\right) P<0.0001$ in unpaired twotailed $t$-test. $(D)$ Relative mRNA expression of the indicated genes analyzed by real-time qPCR. Data are presented with mean and SD $(n=3-4$ mice per group at $5 \mathrm{~W}$ or $6 \mathrm{~W}) .\left(^{*}\right) P<$ 0.05 in unpaired two-tailed $t$-test. $(E)$ Representative liver histology in FF and Gdown1 KO mice at the ages of $5 \mathrm{~W}$. Scale bars, $100 \mu \mathrm{m}$. $(F$, left) Relative mRNA expression of cyclin D1 at $6 \mathrm{~W}$ analyzed by real-time qPCR. Data are presented with mean and SD $(n=4-5$ mice per

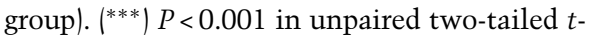
test. (Right) Representative liver histology for cyclin D1-positive hepatocytes in FF and Gdown1 KO mice at 6W. 
staining showed that the DKO hepatocytes were significantly larger than the normal hepatocytes at this stage, with some being extremely enlarged and containing more than three nuclei (Fig. 3D), indicative of incomplete mitoses. Normal liver architecture was obviously distorted, as the pericentral expression pattern of glutamine synthetase (GLUL) was no longer evident in DKO liver (Fig. 3D). Some cells expressed a fetal liver marker, alpha-fetoprotein (AFP), while the expression of cyclin D1 and phosphorylated c-JUN were observed in a majority of the cells
(Fig. 3D). The number of apoptotic cells was dramatically increased at this stage (Fig. 3E), which was accompanied by the proliferation of KRT19-positive cells (Fig. 3D). These results show that, in the absence of p53, Gdown1 $\mathrm{KO}$ causes dysregulated cell cycle progression.

To further investigate the DKO phenotype, transcriptome analysis by RNA-seq was performed. The results showed 1891 up-regulated and 1238 down-regulated genes (Fig. 3F). In particular, the expression of mouse fetal liver markers that include H19, Igf2, and Afp was highly
A

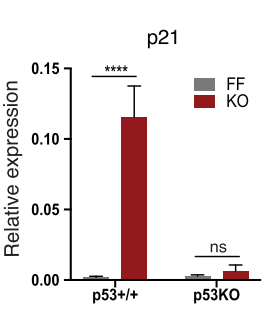

D
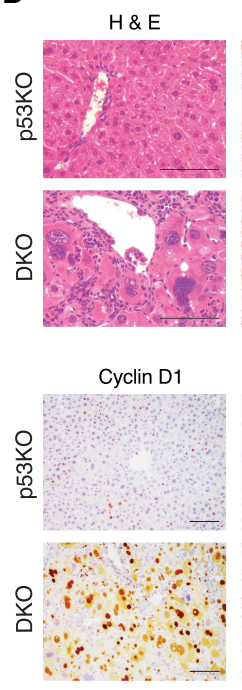

B

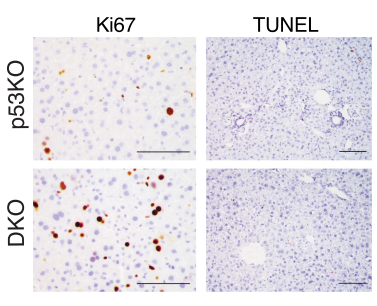

GLUL
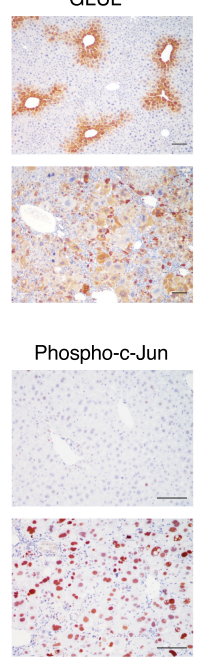

AFP

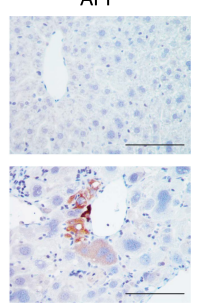

KRT19

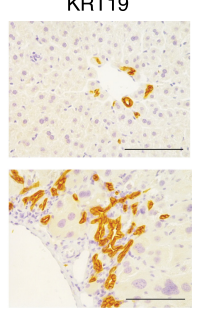

C
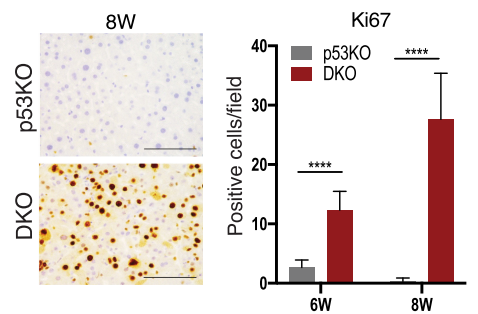

E

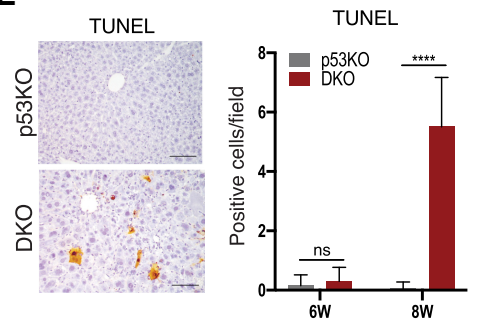

$\mathbf{F}$

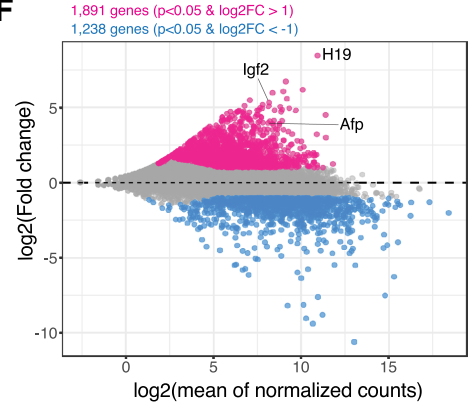

G
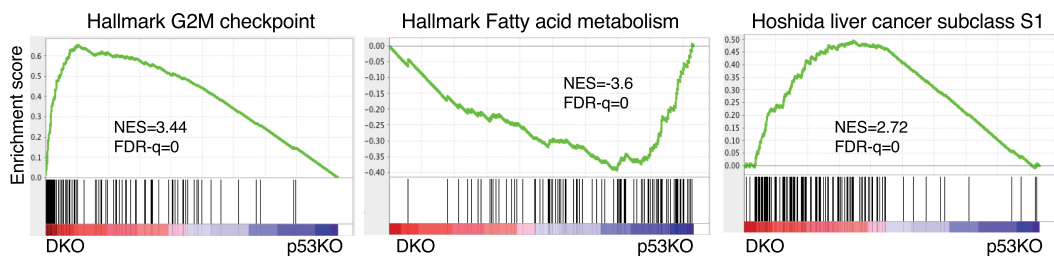

Figure 3. Gdown1 KO causes dysregulated cell cycle progression in the absence of p53. (A) Relative mRNA expression of p21 in the liver from hepatocyte-specific Gdown1 KO mice carrying p53 KO allele (DKO) in comparison with $p 53$ KO liver analyzed by real-time qPCR. Data are presented with mean and SD $\left(n=3-5\right.$ mice at the ages of $6 \mathrm{~W}$ per group. $\left(^{* * * *}\right) P<0.0001$ in unpaired two-tailed $t$-test. $(B)$ Representative liver histology for Ki67- or TUNEL-positive hepatocytes in FF mice carrying p53KO allele (p53KO) and in DKO mice at 6W. Scale bars, $100 \mu \mathrm{m}$. (C, left) Representative liver histology for Ki67-positive hepatocytes in p53KO and DKO mice at 6W. (Right) Quantification of Ki67-positive cells at the indicated ages $(\mathrm{W})$. (D) Representative liver histology in p53KO and DKO mice at 8W. (E, left) Representative liver histology for TUNEL-positive hepatocytes in p53KO and DKO mice at $8 \mathrm{~W}$. Scale bars, $100 \mu \mathrm{m}$. (Right) Quantification of TUNELpositive cells at the indicated ages $(\mathrm{W})$. $(F) \mathrm{MA}$ (minus average) plot for differentially expressed genes in DKO liver at $8 \mathrm{~W}$. Deep pink or light blue color indicates significantly up-regulated or down-regulated genes, respectively $\left(P<0.05\right.$ and $\log _{2}$ fold change $>1$ or $\left.<-1\right)$. $(G)$ Gene set enrichment analysis (GSEA) for differentially expressed genes in DKO liver. 
up-regulated (Fig. 3F). GO analysis revealed that the upregulated genes are enriched in cell cycle, cell adhesion, and immune system processes, while the down-regulated genes are involved in metabolic pathways, particularly in lipid metabolic processes (Supplemental Fig. S3A). The up-regulation of genes, including Aurora kinase genes, that are involved in mitotic nuclear division (Supplemental Fig. S3B) was particularly prominent, which might explain the incomplete mitoses in the DKO phenotype (Fig. 3D). Gene set enrichment analysis (GSEA) further supports the view that the up-regulated genes are enriched in G2M checkpoint genes, E2F target genes, and genes associated with the epithelial-mesenchymal transition (EMT), while the down-regulated genes are enriched in genes associated with fatty acid metabolism (Fig. 3G; Supplemental Fig. S3C). GSEA also revealed that the DKO transcriptome profile is correlated with gene signatures of hepatocellular carcinoma (Fig. 3G; Supplemental Fig. S3D; Lee et al. 2004; Borlak et al. 2005; Acevedo et al. 2008; Cairo et al. 2008; Hoshida et al. 2009; Villanueva et al. 2011). In particular, the profile is similar to that of human HCC subtype S1 tumors, which exhibit more vascular invasion and satellite lesion properties and whose clinical phenotypes show greater risks of earlier recurrence. Also, the molecular pathways that are characteristic of the tumor relate to activation of the WNT pathway in the absence of $\beta$-catenin mutations and up-regulation of TGF- $\beta$ target genes (Hoshida et al. 2009).

Taken together, these results indicate that the Gdown1 $\mathrm{KO}$-induced cell cycle progression is subsequently inhibited by an associated Gdown1 KO induction of $\mathrm{p} 21$ through a p53 pathway. In the absence of p53, cell cycle progression is dysregulated in Gdown1-deficient cells, which show a premalignant-like transformation. These results suggest that Gdown1 plays a critical role in maintaining normal liver function.

\section{Gdown1 is associated with elongating Pol II on genes that} are actively transcribed in the liver

To investigate how the loss of Gdown1 causes hepatocytes to re-enter the cell cycle, and for further insights into normal Gdown1 functions, we tried to identify genes that are directly regulated by $\operatorname{Pol} \mathrm{II}(\mathrm{G})$. To this end, we first examined whether Gdown1 is associated with Pol II in the form of Pol $\mathrm{II}(\mathrm{G})$ in mouse liver. Biochemical analyses (Supplemental Fig. S4A) showed that the majority of Gdown1 in whole-cell extracts treated with NUN buffer containing $1 \mathrm{M}$ urea, and purified by anion exchange chromatography (DEAE), was associated with Pol II (monitored by RPB3), while only a very low amount of Pol IIfree Gdown 1 was isolated by cation exchange chromatography (P11). The result shows that there is little Pol II-free Gdown1 in mouse liver, indicating that Gdown1 plays a direct role in gene transcription through Pol II $(\mathrm{G})$.

To identify genes that are directly targeted by Pol II(G), we performed ChIP-seq analysis with noncross-linked chromatin prepared from FF (control) or Gdown1 KO liver at $7 \mathrm{~W}$ of age. Surprisingly, significant Gdown1 enrichment was observed in gene bodies of highly expressed genes in the liver (Fig. 4A). Among these genes, Alb, Serpina3k, and Apob encode plasma proteins that are constitutively produced in the liver. Cyp2e1 encodes a member of the cytochrome p450 family that is involved in xenobiotic metabolism, while Cps1 encodes a mitochondrial enzyme involved in the urea cycle. These genes play a major role in the maintenance of normal liver functions. Notably, the anti-Gdown1 ChIP signals seen in control FF liver were not detected in Gdown1 KO liver, showing that the observed enrichment signals are Gdown1-specific (Fig. 4A). Also, weaker Gdown1 signals were seen around the promoter-proximal regions compared with the gene bodies (Supplemental Fig. S4B), in contrast to what was previously reported in studies lacking Gdown1 knockout or knockdown cell controls (Cheng et al. 2012). Notably, in knockout cells the Pol II signals on direct Gdown1 target genes were substantially decreased (Fig. 4A,B), whereas Pol II enrichment was increased on genes, such as Cdo1, and $\operatorname{Arg} 1$, that were not directly targeted by Gdown1 (Fig. 4B). The expression of immediate early genes such as Jun, Fos, and Btg2 is induced in the priming phase of liver regeneration (Thompson et al. 1986; Mohn et al. 1990). Although these genes are regulated by paused Pol II at their promoter proximal regions (Liu et al. 2015), Gdown1 was not detected on these genes (Fig. 4C). Importantly, Gdown 1 also was not observed on genes that are involved in cell cycle progression (Fig. 4C), indicating that Gdown1 $\mathrm{KO}$-induced cell cycle re-entry is clearly through secondary (indirect) effects.

As previously reported for primary human lung fibroblast cells (Jishage et al. 2012), the number of genes that are directly targeted by Gdown1 appears to be very low, as peak calling analyses identified only 222 such genes. Plotting region scores of these genes from ChIP-seq analysis with the corresponding transcripts (transcripts per million [TPM]) from RNA-seq data showed that 54 of the targeted genes are highly expressed genes in the liver $(\mathrm{TPM}>1000$ ) (shown in red circles in Fig. 4D). Gdown1 was also observed in the promoter regions of several genes (Supplemental Fig. S4C) that tend to be categorized as lowly expressed genes (shown in triangles in Fig. 4D). GO analysis revealed that the majority of Gdown1 targeted genes are involved in plasma protein synthesis and metabolic pathways (Fig. 4E). Consistent with the decreased Pol II recruitment upon loss of Gdown1, differential expression analysis showed that mRNA expression of the direct Gdown 1 target genes was down-regulated in $\mathrm{KO}$ liver (indicated by triangle-enclosed circles in Fig. 4F).

In FF liver, transcripts of 122 genes (transcripts per million $[\mathrm{TPM}]>1000$ ) account for $\sim 50 \%$ of the entire liver mRNA, with about $44 \%$ of the corresponding genes being occupied by Pol II(G) (Fig. 4G). Although the number of genes that were identified as Pol II (G) direct target genes seems to be quite low $(<0.4 \%$ of the total number of expressed genes), $\sim 30 \%$ of total mRNA synthesis is derived from genes directly regulated by $\mathrm{Pol} \mathrm{II}(\mathrm{G})$ transcription (Fig. 4G). Also, TPM count analysis showed that the total transcripts of highly expressed genes (TPM > 1000) were decreased in the $\mathrm{KO}$, while the remaining gene transcripts were significantly increased (Fig. 4H). 
A

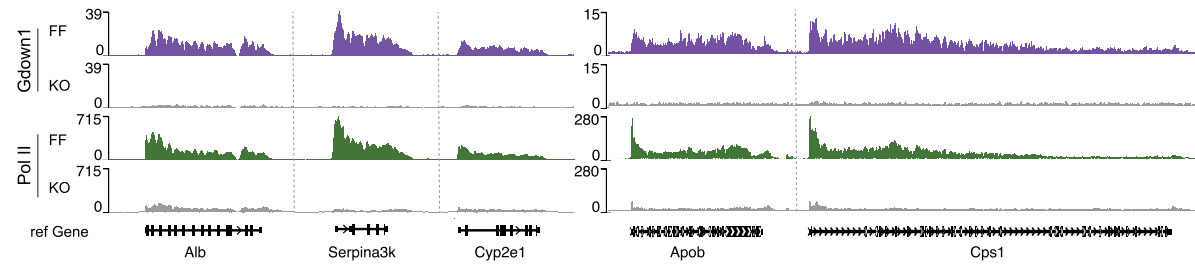

B

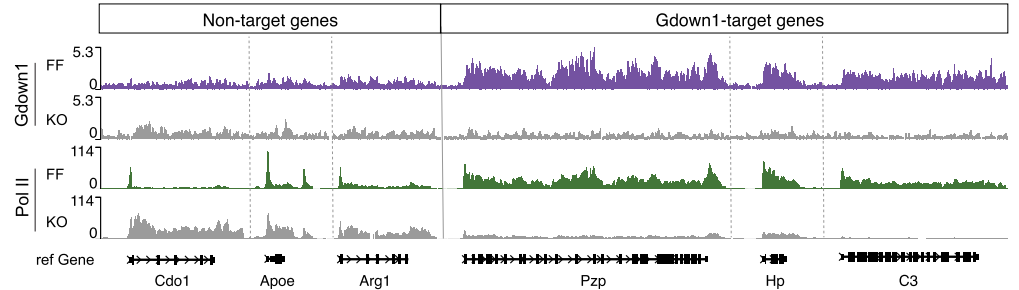

C

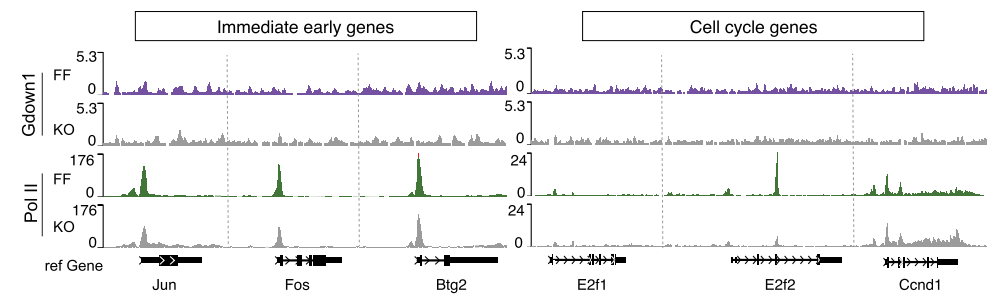

D

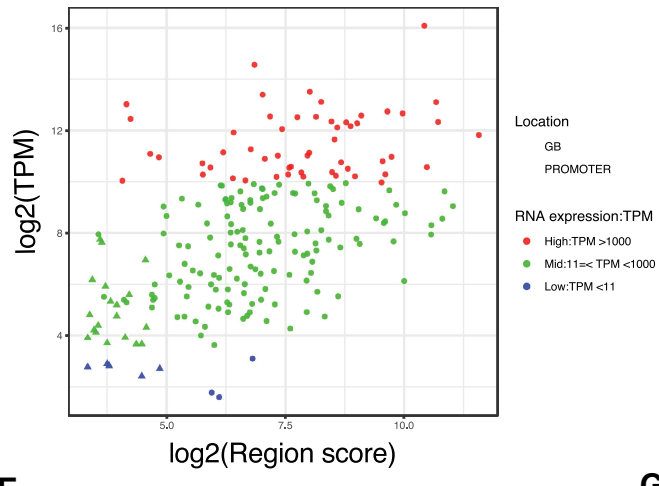

E

\begin{tabular}{lrrr} 
GO & Count & \multicolumn{1}{c}{$\%$} & PValue \\
\hline GO:0070062 extracellular exosome & 78 & 35.3 & $4.15 \mathrm{E}-18$ \\
GO:0072562 blood microparticle & 21 & 9.5 & $8.37 \mathrm{E}-18$ \\
GO:0055114 oxidation-reduction process & 30 & 13.6 & $4.95 \mathrm{E}-10$ \\
mmu01100:Metabolic pathways & 51 & 23.1 & $1.61 \mathrm{E}-09$ \\
\hline
\end{tabular}

G
$\mathbf{F}$
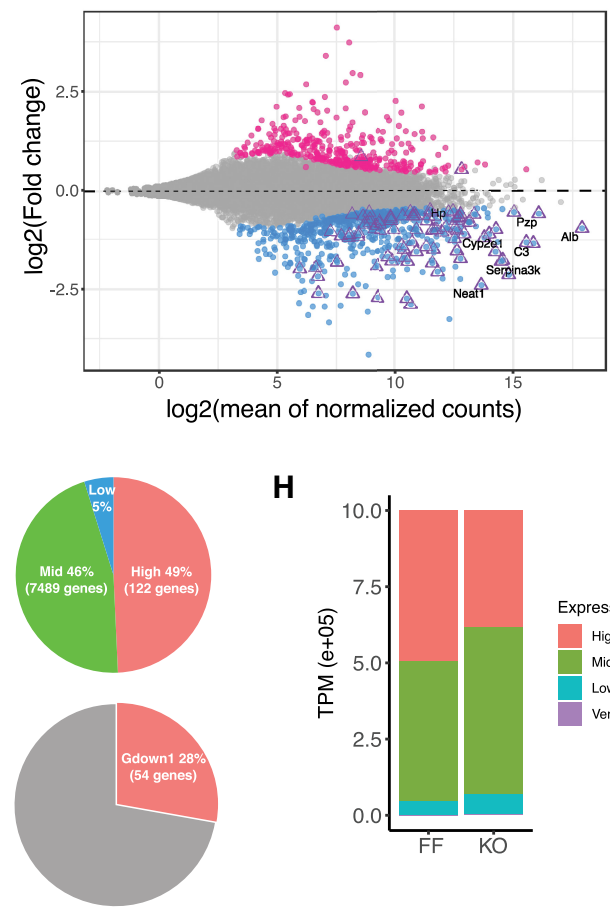

H

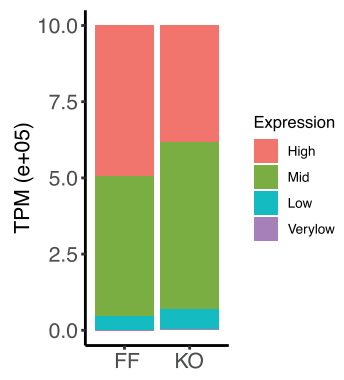

Figure 4. Gdown 1 is associated with elongating Pol II on genes that are actively transcribed in the liver. $(A-C)$ ChIP-seq profiles generated with Gdown1 and RPB3 (Pol II) antibodies at the indicated genes in FF and Gdown1 KO liver. $(D)$ Gdown1 target genes that were plotted by transcripts per million (TPM) and ChIP-seq region score. (E) Gene ontology analysis for Gdown1 target genes. (F) MA plot for differentially expressed genes in Gdown1 KO liver at the age of 7W. Deep pink or light blue color indicates significantly up-regulated or down-regulated genes, respectively $\left(P<0.05\right.$ and $\log _{2}$ fold change $>0$ or $\left.<0\right)$. Gdown1 target genes are indicated with triangles in purple color. $(G, t o p)$ The percentages of transcripts (TPM) for high-expressed genes (TPM $>1000$, shown in red), mid-expressed genes $(11 \leq \mathrm{TPM}<1000$, shown in green), and low-expressed genes (TPM < 11, shown in blue) in FF liver. (Bottom) The percentage of transcripts for Gdown1 targeted, highly expressed genes in FF liver. (H) The percentages of transcripts (TPM) in Gdown1 KO liver for high, mid, and low expressed genes groups that were categorized in FF liver. (High) TPM > 1000; (mid) $11 \leq \mathrm{TPM}<1000$; (low) $1 \leq \mathrm{TPM}<11$; (very low) TPM $<1$ ). 
In summary, the majority of Gdown1 is detected in association with elongating Pol II on direct target genes that are important for maintaining normal liver functions, suggesting that Gdown1 is directly involved in regulation of the expression of select genes.

Expression of direct Gdown1 target genes is inversely correlated with expression of cell cycle-related genes

Although Gdown1 KO leads initially to cell cycle re-entry, the nature of the down-regulated genes in the KO hepatocytes indicates that Gdown1 is not directly involved in transcription of the up-regulated cell cycle-related genes. Rather, the down-regulated expression of Gdown1 direct target genes (identified by the ChIP-seq) seems to be the primary effect of the Gdown1 KO relating to cell cycle re-entry. However, since the Gdown1 KO resulting from Alb-Cre expression is complete by $5 \mathrm{wk}$, this down-regulation of Gdown1 direct target gene expression in the KO could be due to secondary effects. Therefore, to investigate more immediate effects of the Gdown1 KO, we generated tamoxifen-inducible $G$ down $1^{f / f}(\mathrm{KO})$ mice carrying both the Alb-CreERT2 transgene and a p53 null mutation (designated DKO ${ }^{A l b-C r e E R T 2}$ mice). Around $6 \mathrm{~h}$ after tamoxifen injection, the level of Gdown1 protein relative to the level of the RPB3 subunit of Pol II was significantly decreased, and by $14 \mathrm{~h}$ declined to nearly undetectable levels (Fig. 5A).

Histological analyses showed that DKO ${ }^{A l b-C r e E R T 2}$ hepatocyte nuclei were enlarged relative to p53 KO hepatocyte nuclei (H\&E staining in Fig. 5B). Cyclin D1 expression was detected in some $\mathrm{DKO}^{A l b-C r e E R T 2}$ hepatocytes within $24 \mathrm{~h}$ after tamoxifen injection and was observed in most hepatocytes at 48 h (Fig. 5B). Similarly, significant numbers of $\mathrm{DKO}^{A l b-c r e E R T 2}$ hepatocytes were Ki67-positive within $24 \mathrm{~h}$ (Fig. 5B). These results show that $\mathrm{DKO}^{A l b \text {-creERT2 }}$ hepatocytes re-enter the cell cycle quite rapidly.

Consistent with the results observed in the Gdown1 f/f;Alb-Cre (KO) hepatocytes (Fig. 4F), albumin mRNA expression in DKO ${ }^{A l b-c r e E R T 2}$ hepatocytes gradually decreased within $48 \mathrm{~h}$ after tamoxifen injection, while cyclin A2 expression dramatically increased (Fig. 5C). To further analyze the inversely correlated expression, we performed ChIP-seq combined with RNA-seq using liver from DKO ${ }^{A l b-c r e E R T 2}$ mice treated with tamoxifen for $24 \mathrm{~h}$. ChIP-seq profiles showed that the Gdown1 KO led to decreased Pol II occupancies on the direct target genes (Fig. 5D). Consistent with the results observed in KO hepatocytes (Fig. 4F), RNA-seq analysis in DKO ${ }^{A l b-c r e E R T 2}$ hepatocytes showed that expression of a majority of the direct Gdown1 target genes (purple triangle-enclosed circles in Fig. 5E) were down-regulated upon loss of Gdown1. Noted exceptions were eight genes, including Fgg and Fga (indicated in Fig. 5E), whose expression was moderately up-regulated $(<1.5$-fold). Consistent with these RNA-seq results, ChIP-seq profiles showed that the Pol II signal on the Fgg gene body was unaffected even though Gdown1 was no longer detected (Supplemental Fig. S5A). However, Pol II recruitment on this gene was decreased in $\mathrm{KO}^{\text {Alb-cre }}$ hepato- cytes at 7W (Supplemental Fig. S5B), which suggests that the kinetics of an impact of Gdown1 loss on Pol II recruitment may vary depending on the specific gene. GO analysis for differentially expressed genes in DKO ${ }^{\text {Alb-creERT2 }}$ hepatocytes showed results similar to those observed (Supplemental Fig. S3A) for the down-regulated genes in $\mathrm{DKO}^{\text {Alb-Cre }}$ hepatocytes, with the up-regulated genes being particularly enriched not only in cell cycle-related genes but also in genes related to mitochondrial and RNA metabolism (Fig. 5F; Supplemental Fig. S5C).

In relation to the up-regulated genes in $\mathrm{DKO}^{\text {Alb-CreERT2 }}$ hepatocytes, the Snrnp200 gene that encodes the small nuclear ribonucleoprotein U5 subunit 200 is one of the up-regulated spliceosome genes indicated by GO analysis (Supplemental Fig. S5C). The ChIP-seq profile clearly shows increased Pol II recruitment to the promoter region

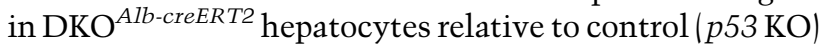
hepatocytes (Fig. 5G). Similar Pol II ChIP-seq profiles, with increased Pol II recruitment to promoter regions, were also observed for the up-regulated cell cycle-related $A$ urkb and $C d c 20$ genes (Fig. 5G). The up-regulated Polr2a, encoding the RPB1 subunit of Pol II, showed a reduction in the level of a strong paused Pol II at the promoter and a reciprocal increase in elongating Pol II in $\mathrm{DKO}^{\text {Alb-creERT2 }}$ hepatocytes relative to p53 KO hepatocytes (Fig. 5G). As predicted, Gdown1 was not detected on these up-regulated genes in p53 KO hepatocytes, indicating that their up-regulation upon Gdown1 loss is indeed through indirect effects of Gdown1.

Since Pol II recruitment to direct Gdown1 target genes rapidly decreases in the $\mathrm{DKO}^{\text {Alb-CreERT2 }}$ liver, the normal role of Gdown1 on Pol II in the bodies of these genes remains unclear. However, there are several genes whose transcripts were increased in $\mathrm{DKO}^{A l b-C r e E R T 2}$ liver by a seemingly failed termination of transcription of an adjacent Gdown1 target gene, as exemplified by the following. Expression of Sftpa1, which encodes the surfactant associated protein A1, is normally restricted to adult lung but increased in $\mathrm{DKO}^{\text {Alb-CreERT2 }}$ liver (Supplemental Fig. S5D). Interestingly, on Mat1a, a down-regulated direct Gdown1 target gene that is located just upstream of Sftpa1 (Supplemental Fig. S5E), Pol II was detected continuously from the termination site of Mat1a to the gene body of Sftpa1 in $\mathrm{DKO}^{\text {Alb-CreERT2 }}$ liver, implying a potential role for Gdown1 in transcription termination of Sftpa1 and read-through of the downstream gene in the absence of Gdown1.

Altogether, the results indicate that Gdown1 KO can rapidly (within $24 \mathrm{~h}$ ) stimulate hepatocytes to re-enter into the cell cycle in the absence of p53. Notably, the down-regulated expression of direct Gdown1 target genes upon Gdown1 loss appears to be inversely correlated with the expression of genes that are involved in cell cycle control and mitochondrial and RNA metabolism.

\section{Down-regulation of highly expressed genes in the liver proceeds the cell cycle re-entry}

Although the tamoxifen-inducible Gdown1 KO results in $\mathrm{DKO}^{\text {Alb-CreERT2 }}$ liver clearly show an inverse correlation between the expression of direct Gdown1 target genes 
A

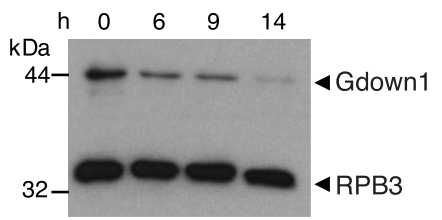

C

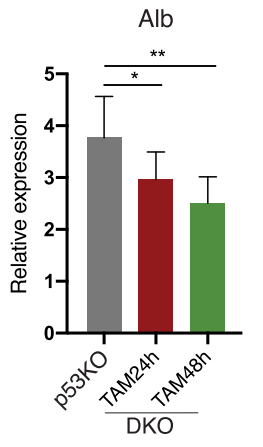

D

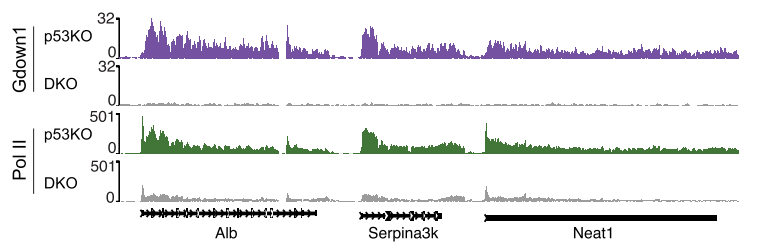

G
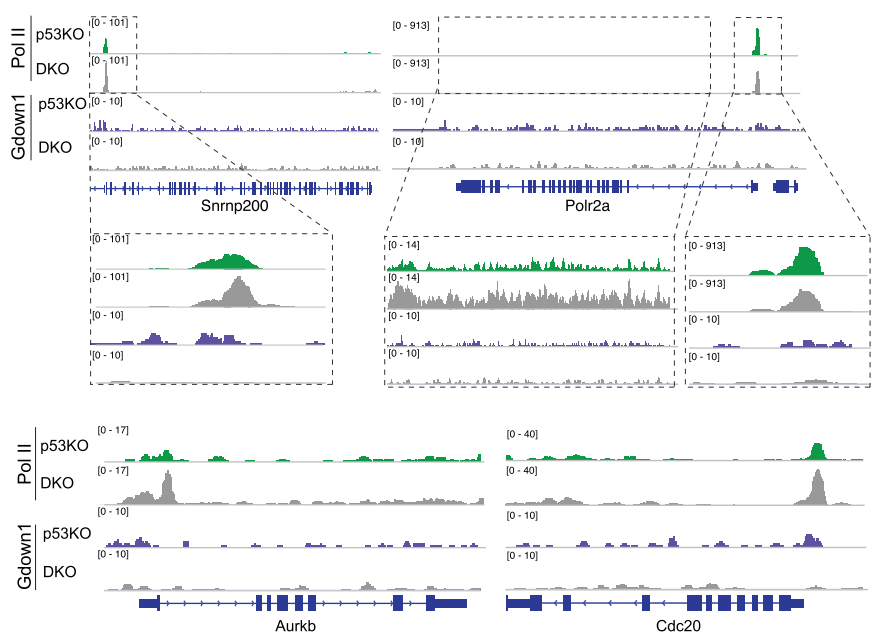

B
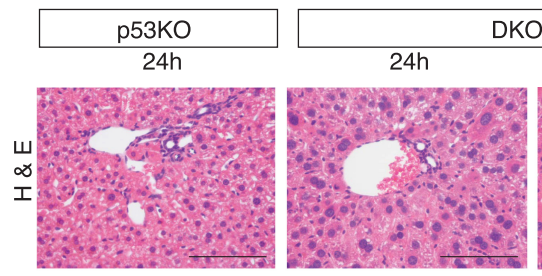
$\frac{\text { DKO }}{\text { AlbcreERT2 }}$
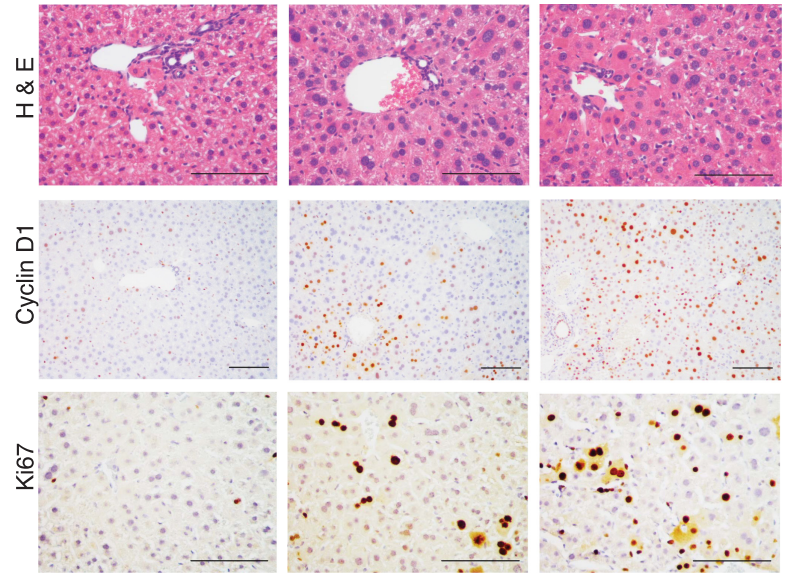

E

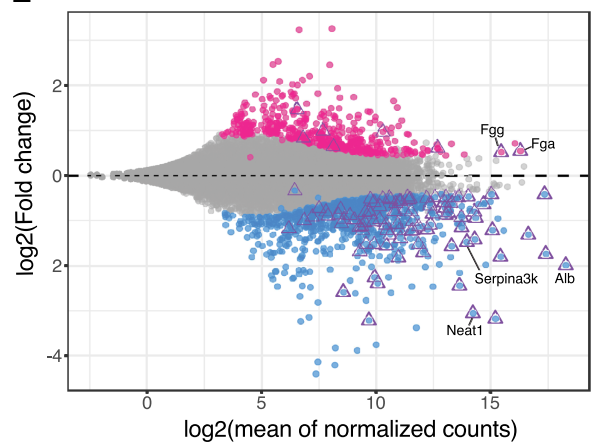

$\mathbf{F}$

\begin{tabular}{lrll}
$\begin{array}{l}\text { Up-regulated genes (467 genes) } \\
\text { Term }\end{array}$ & Count & \multicolumn{1}{l}{$\%$} & PValue \\
\hline GO:0005739 mitochondrion & 72 & 16.6 & $8.03 \mathrm{E}-09$ \\
GO:0044822 poly(A) RNA binding & 51 & 11.8 & $1.97 \mathrm{E}-07$ \\
GO:0005743 mitochondrial inner membrane & 25 & 5.8 & $1.61 \mathrm{E}-06$ \\
mmu03040:Spliceosome & 15 & 3.5 & $3.32 \mathrm{E}-06$ \\
Cell division & 22 & 5.1 & $8.92 \mathrm{E}-06$ \\
Cell cycle & 30 & 6.9 & $9.12 \mathrm{E}-06$ \\
mRNA splicing & 17 & 3.9 & $1.41 \mathrm{E}-05$ \\
GO:0006635 fatty acid beta-oxidation & 8 & 1.8 & $3.03 \mathrm{E}-05$ \\
GO:0015030 Cajal body & 8 & 1.8 & $4.40 \mathrm{E}-05$ \\
\hline Down-regulated genes (868 genes) & & & \\
Term & Count & $\%$ & PValue \\
\hline GO:0070062 extracellular exosome & 225 & 29.9 & $2.06 \mathrm{E}-36$ \\
mmu01100:Metabolic pathways & 162 & 21.5 & $2.92 \mathrm{E}-28$ \\
GO:0016491 oxidoreductase activity & 89 & 11.8 & $3.01 \mathrm{E}-27$ \\
GO:0005783 endoplasmic reticulum & 132 & 17.5 & $5.76 \mathrm{E}-27$ \\
GO:0043231 intracellular membrane-boundec & 93 & 12.4 & $2.27 \mathrm{E}-25$ \\
GO:0006629 lipid metabolic process & 71 & 9.4 & $8.74 \mathrm{E}-24$ \\
\hline
\end{tabular}

Figure 5. Expression of Gdown1 target genes is inversely correlated with expression of cell cycle-related genes. $(A)$ Gdown 1 expression in liver after tamoxifen injection in FF mice carrying both the p53 KO allele and Alb-creERT2 (DKO $\mathbf{A l b}^{\text {-creERT2 }}$ mice) at the indicated times. Liver nuclear pellets were analyzed by immunoblot. RPB3 serves as a loading control. $(B)$ Representative liver histology in $p 53 \mathrm{KO}$ and $\mathrm{DKO}^{\text {Alb-creERT2 }}$ mice at the indicated times. Scale bars, $100 \mu \mathrm{m}$. (C) Relative mRNA expression of albumin $(A l b)$ and cyclin A2 genes analyzed by real-time qPCR. Control, $p 53 \mathrm{KO}$ mice treated with tamoxifen for $24 \mathrm{~h}(n=9)$. TAM24h and TAM48h, DKO ${ }^{\text {Alb-creERT2 }}$ mice treated with tamoxifen for 24 or $48 \mathrm{~h}(n=7$ or 5$)$, respectively. Data are presented with mean and SD. $\left({ }^{*}\right) P<0.05 ;\left({ }^{* *}\right) P<0.01 ;\left({ }^{* * * *}\right) P<$ 0.0001 in unpaired two-tailed $t$-test. $(D)$ ChIP-seq profiles generated with Gdown1 and RPB3 (Pol II) antibodies at the indicated genes in p53KO and DKO ${ }^{\boldsymbol{A l b} \text {-creERT2 }}$ liver. (E) MA plot for differentially expressed genes in DKO ${ }^{\boldsymbol{A l b} \text {-creERT2 }}$ liver treated with tamoxifen for $24 \mathrm{~h}$. Deep pink or light blue indicates significantly up-regulated or down-regulated genes, respectively $\left(P<0.05\right.$ and $\log _{2}$ fold change $>0$ or $<0)$. Direct Gdown1 target genes are indicated with triangle-enclosed circles. $(F)$ Gene ontology analysis for differentially expressed genes in DKO ${ }^{\text {Alb-creERT2 }}$ liver. $(G)$ ChIP-seq profiles generated with Gdown1 and RPB3 (Pol II) antibodies at the indicated genes in p53KO and DKO (DKO $\left.{ }^{\text {Alb-creERT2}}\right)$ liver. 
and cell cycle-related genes, it remains unclear how the DKO hepatocytes can re-enter into the cell cycle. To investigate the basis for the re-entry, we analyzed $\mathrm{DKO}^{\text {Alb-CreERT2 }}$ liver at an earlier time point $(16 \mathrm{~h})$ after tamoxifen administration. Notably, two distinct groups of $\mathrm{DKO}^{\text {Alb-CreERT2 }}$ livers were distinguished with respect to the level of cyclin D1 RNA expression (indicated as "high" and "low" in Fig. 6A), while Alb RNA expression was significantly down-regulated in almost all cases (Fig. 6A). Histological analyses further indicated the absence of cyclin D1- and Ki67-positive cells in DKO ${ }^{\text {Alb-CreERT2 }}$ livers with the low level of cyclin D1 RNA expression (indicated as "low" in Fig. 6B). For DKO ${ }^{A l b-C r e E R T 2}$ livers with the high level of cyclin D1 RNA expression, there were subgroups that were either cyclin D1 positive and
Ki67 negative or both cyclin D1-positive and Ki67-positive (identified as "high" in Fig. 6B), indicating normal cell cycle progression in which cyclin D1 expression proceeds prior to Ki67 expression. ChIP-qPCR analyses further revealed that the amounts of Pol II on the bodies of at least two genes, the $A l b$ and $C 3$ genes that are direct Gdown1 target genes, were significantly decreased in the group with the low level of cyclin D1 RNA expression (Fig. 6C). This result shows that the down-regulation of these direct Gdown1 target genes occurs prior to cyclin D1 expression. However, not all of the target genes were down-regulated simultaneously. For Serpina3k, one of the direct Gdown1 target genes, the decrease of Pol II in the gene body was not observed in the group with the low level of cyclin D1 but was observed in the group
A

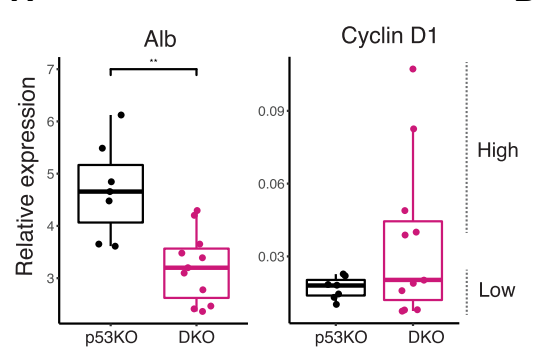

C
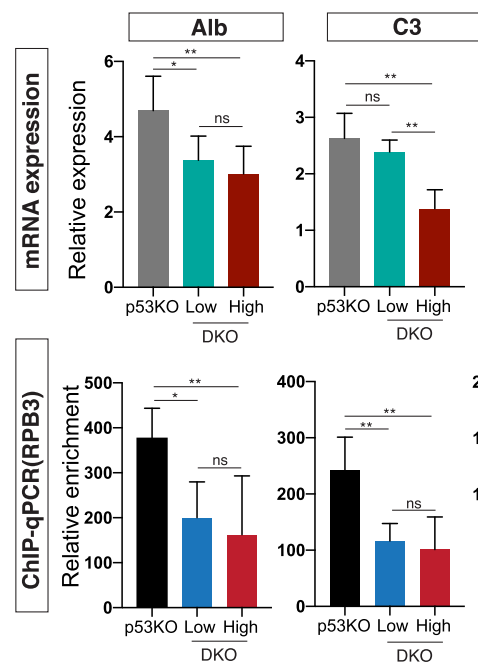
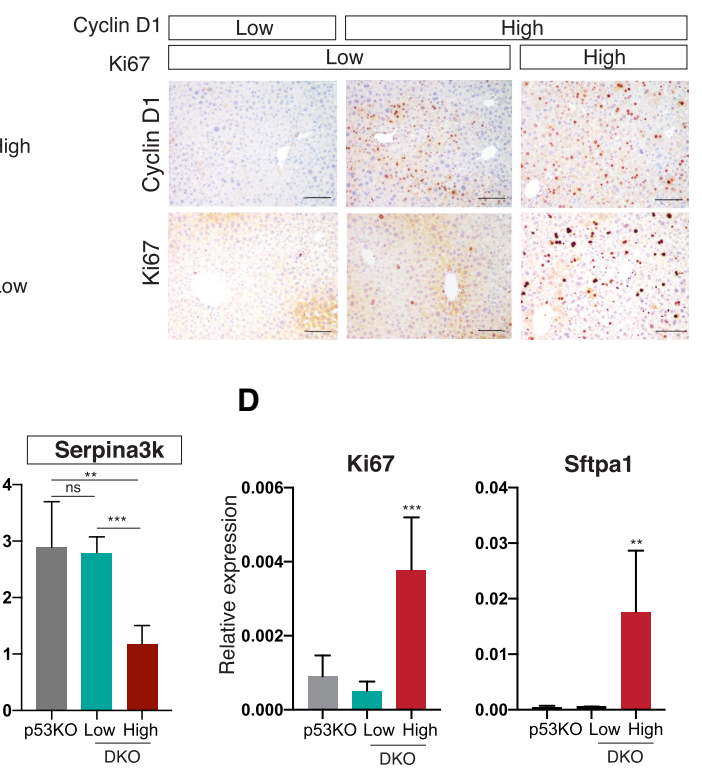

D
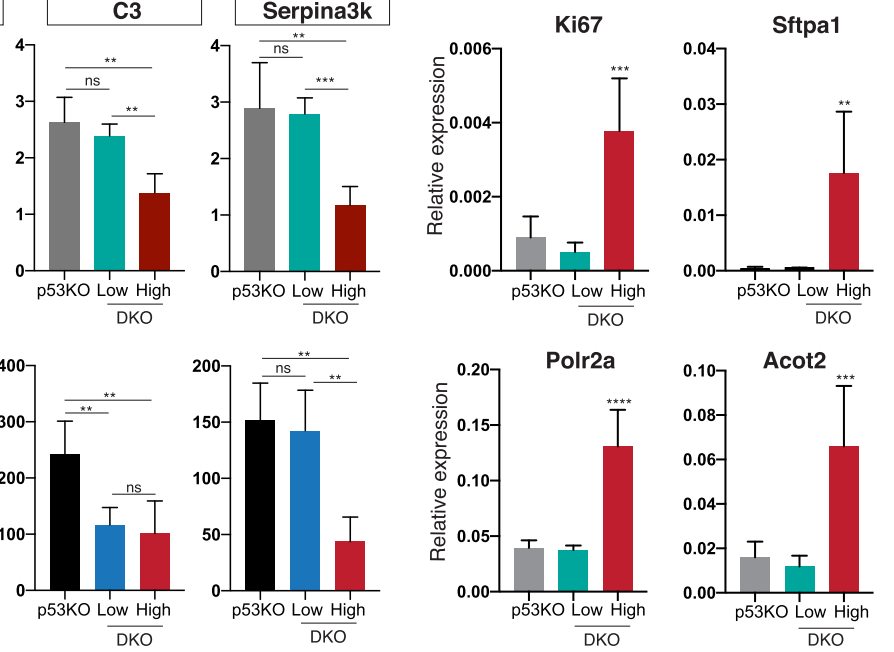

Figure 6. Down regulation of highly expressed genes in the liver induces cell cycle re-entry. (A) Relative mRNA expression of albumin $(A l b)$ and cyclin D1 genes analyzed by real-time qPCR. (Control) $p 53 \mathrm{KO}$ mice treated with tamoxifen for $16 \mathrm{~h}(n=7) ;(\mathrm{DKO})$ $\mathrm{DKO}^{\boldsymbol{A l b} \text {-creERT2 }}$ mice treated with tamoxifen for $16(n=11) .\left(^{* *}\right) P<0.01$, in unpaired two-tailed $t$-test. Two distinct groups of $\mathrm{DKO}^{\text {Alb-creERT2 }}$ livers, in terms of the level of cyclin D1 RNA expression, are indicated as "high" $(n=5)$ and "low" $(n=6)$. (B) Representative liver histology in DKO ${ }^{\text {Alb-creERT2 }}$ mice expressing high or low levels of cyclin D1 and Ki67. Scale bars, $100 \mu \mathrm{m}$. (C, top) Relative mRNA expression of the indicated genes analyzed by real-time qPCR. (Bottom) Relative enrichment of Pol II on the gene bodies for the indicated genes analyzed by real-time qPCR. (Control) p53 KO mice treated with tamoxifen for $16 \mathrm{~h}(n=7$ mice per group); (low or high) DKO ${ }^{A I b-c r e E R T 2}$ mice treated with tamoxifen for $16 \mathrm{~h}$ and expressing low or high levels of cyclin D1 ( $n=6$ or 5 mice per group). Data are presented with mean and SD. $\left(^{*}\right) P<0.05 ;\left(^{* *}\right) P<0.01 ;\left(^{* * *}\right) P<0.001$ in unpaired two-tailed $t$-test. $(D)$ Relative mRNA expression of the indicated genes analyzed by real-time qPCR. (Control) p53 KO mice treated with tamoxifen for $16 \mathrm{~h}$ ( $n=7 \mathrm{mice}$ per group); (low or high) DKO ${ }^{\text {Alb-creERT2 }}$ mice treated with tamoxifen for $16 \mathrm{~h}$ and expressing low or high levels of cyclin D1 ( $n=6$ or 5 mice per group). Data are presented with mean and SD. $\left(^{* *}\right) P<0.01 ;\left(^{* * *}\right) P<0.001 ;\left(^{* * *}\right) P<0.0001$ in unpaired two-tailed $t$-test. 
with the high level of cyclin D1 (Fig. 6C), suggesting that the time it takes to see an impact of Gdown1 loss on Pol II recruitment is gene-dependent.

Genes that might be induced by Gdown1 KO prior to activation of cyclin D1 expression could be involved in the direct cause of the cell cycle re-entry. Therefore, RNA expression levels were assessed for several genes that were up-regulated in $\mathrm{DKO}^{A l b \text {-CreERT2 }}$ liver at $24 \mathrm{~h}$. However, no induction of these genes was observed in the liver group with low levels of cyclin D1 (Fig. 6D). We also analyzed expression of immediate early genes whose expression is induced at the early stage of liver regeneration, although no induction of four such genes (Myc, Jun, Fos, and Btg2) was observed in the group with the low levels of cyclin D1 RNA expression (Supplemental Fig. S6A).

As previously reported, overexpression of cyclin D1 is sufficient to induce hepatocyte proliferation in vivo (Nelsen et al. 2001; Mullany et al. 2008). As the Gdown1 KOinduced cell cycle re-entry could simply be stimulated by the induction of cyclin D1 expression, we investigated the mechanism of the induction. Cyclin D1 expression is regulated by both transcriptional and posttranscriptional mechanisms (Witzel et al. 2010). ChIP-qPCR analysis showed that Pol II recruitment was increased at the promoter region of cyclin D1 in DKO ${ }^{A l b-C r e E R T 2}$ liver with the high cyclin D1 RNA expression (Supplemental Fig. $\mathrm{S} 6 \mathrm{~B})$, indicating that the cyclin D1 induction involves transcriptional activation. It is known that cyclin D1 expression is mitogen-activated, and its promoter is regulated by multiple transcription factors (Klein and Assoian 2008) that include STAT3, c-JUN, NF-кB, and $\beta$-catenin. Although it appears that there is no obvious liver damage that might activate a mitogenic signaling pathway in $\mathrm{DKO}^{A l b-C r E E R T 2}$ liver, the nuclear localization of these transcription factors was analyzed by immunoblotting of nuclear pellets. Whereas acute injury by carbon tetrachloride induced the expression of $\beta$-catenin, phosphorylated STAT3, and NF- $\mathrm{kB}(\mathrm{p} 65)$ in the nucleus at $12 \mathrm{~h}$ after administration (Supplemental Fig. S6C, lane 9 vs. lanes $10,11), \beta$-catenin induction was not observed in the $\mathrm{DKO}^{\text {Alb-CreERT2 }}$ liver (Supplemental Fig. S6C, lanes 4-8 vs. lane 9 or lanes 10,11). Nuclear-localized phosphorylated STAT3, as well as NF- $\mathrm{BB}$, was detected in several

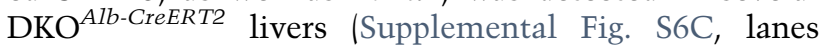
$5,6,8)$. However, expression levels were not proportionally correlated with cyclin D1 mRNA expression levels, such that the immediate molecular basis for cyclin D1 induction in $\mathrm{DKO}^{A l b-C r e E R T 2}$ liver remains to be determined.

\section{Expression of highly expressed liver-specific genes are inversely correlated with expression of cell cycle-related genes in hepatocellular carcinoma}

Although the mechanism of cyclin D1 induction remains unknown, the down-regulation of Gdown1-associated genes, especially those highly expressed in the liver, appears to be correlated with cell cycle re-entry. Supporting this idea, a differential expression analysis of a TCGA hepatocellular carcinoma (HCC) cohort with high-impact p53 mutations from public patient data sets revealed an inverse correlation between the expression of cell cycleinvolved genes and highly expressed genes in the liver (Fig. 7A). Compared with the normal liver tissue (Cluster1 in Fig. 7A), the inverse correlation is quite evident for Cluster 2, while Clusters 3 and 4 show partial correlation (Fig. 7A; Supplemental Fig. S7A). Homeobox genes and tumor antigens were highly expressed in the HCC cohort. However, an inverse correlation of these genes with highly expressed genes in the liver is less clear than the inverse correlation of the highly expressed genes with cell cycleinvolved genes (Supplemental Fig. S7B, C). CENPF is a kinetochore protein (Liao et al. 1995), whose overexpression is frequently observed in various cancers including HCC (Dai et al. 2013). The inverse correlation between albumin and CENPF is more convincing compared with a homeobox protein, HOXA9 (Fig. 7B).

Overall, these latter results suggest that the downregulation of highly expressed genes in the liver may contribute to hepatocyte proliferation leading to tumor development.

\section{Discussion}

In this study, we report a direct positive role of the Pol IIassociated factor Gdown1 in the regulation of gene transcription to maintain normal liver functions. Gdown1 is bound to Pol II as Pol II (G) in the liver and localized to the gene bodies of highly transcribed genes. The loss of Gdown1, through a hepatocyte-specific Gdown1 knockout (KO), leads to the down-regulation of these genes, which in turn activates expression of cell cycle regulatory genes and leads to hepatocyte re-entry into the cell cycle. However, this cell cycle re-entry is ultimately countered by a Gdown1 KO-mediated, p53-dependent induction of p21- as revealed by a facilitated cell cycle entry and resultant cell cycle dysregulation with a double knockout of Gdown1 and p53. Most importantly, these results establish an important and newly recognized physiological function for an RNA polymerase II regulatory factor (Gdown1) in the maintenance of normal liver cell transcription through a direct effect on highly transcribed liver-specific genes and complementary constraints on cell cycle re-entry of quiescent hepatocytes.

Consistent with results of our previous study of Drosophila Gdown1 (Jishage et al. 2018), our finding that Gdown1 KO mice are embryonic lethal indicates an essential role for Gdown1 in mouse early embryonic development. However, Gdown1 hepatocyte KO mice appear to be normal and healthy, suggesting that the loss of Gdown1 is not lethal for quiescent cells such as hepatocytes. Although the observed phenotype in the Gdown 1 $\mathrm{KO}\left(\mathrm{KO}^{A l b-C r e}\right)$ liver is relatively less severe compared with the p53;Gdown1 double-knockout (DKO ${ }^{\text {Alb-Cre }}$ ) liver, the major impact on the liver is the continuous expression of cyclin D1 followed by activation of p53 signaling pathways. Although the cell cycle progression of Gdown1 KO hepatocytes observed at 5 wk is subsequently countered by p53-induced p21, a significant number of cells re-enter the cell cycle or succumb to apoptosis by $8 \mathrm{wk}$. 
Jishage et al.

A

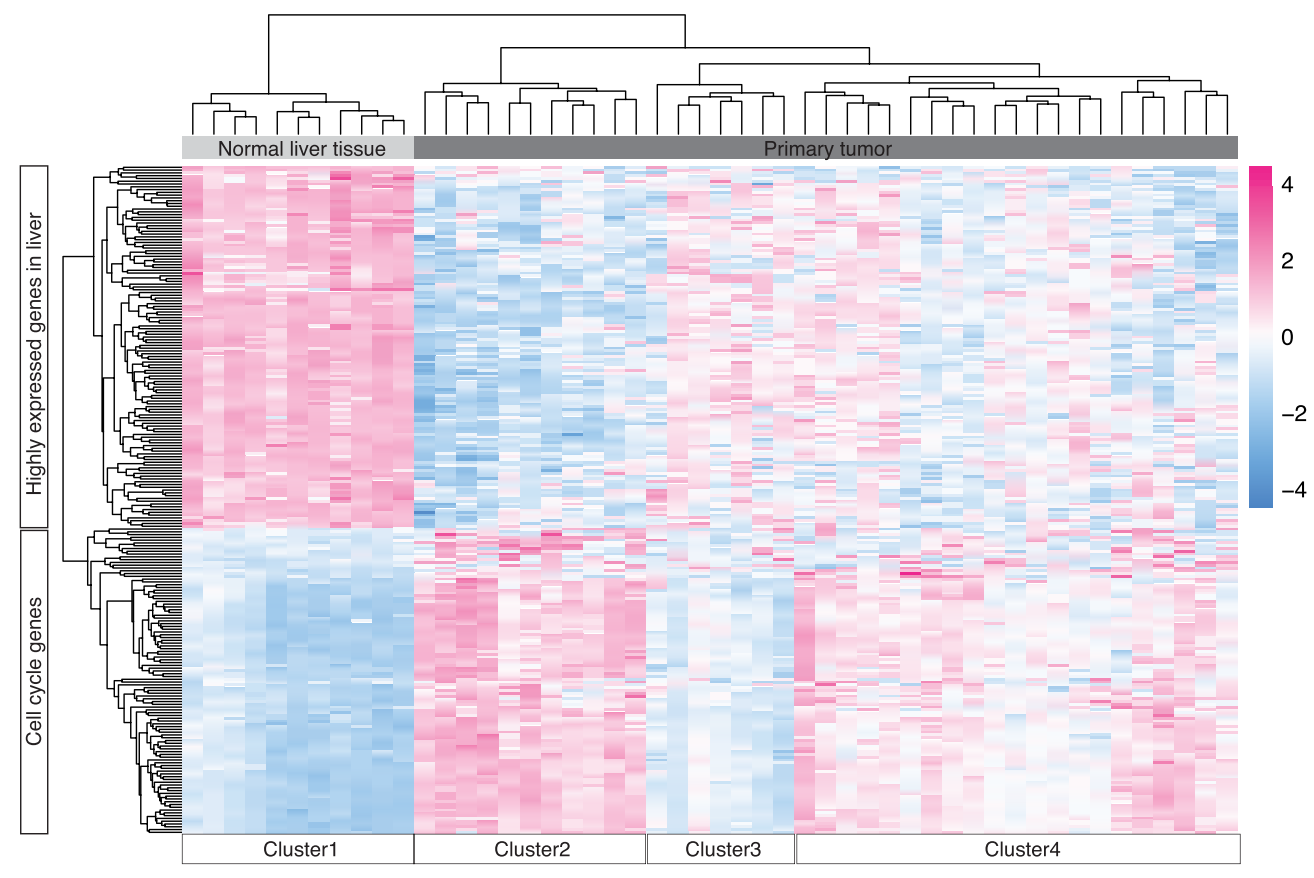

B
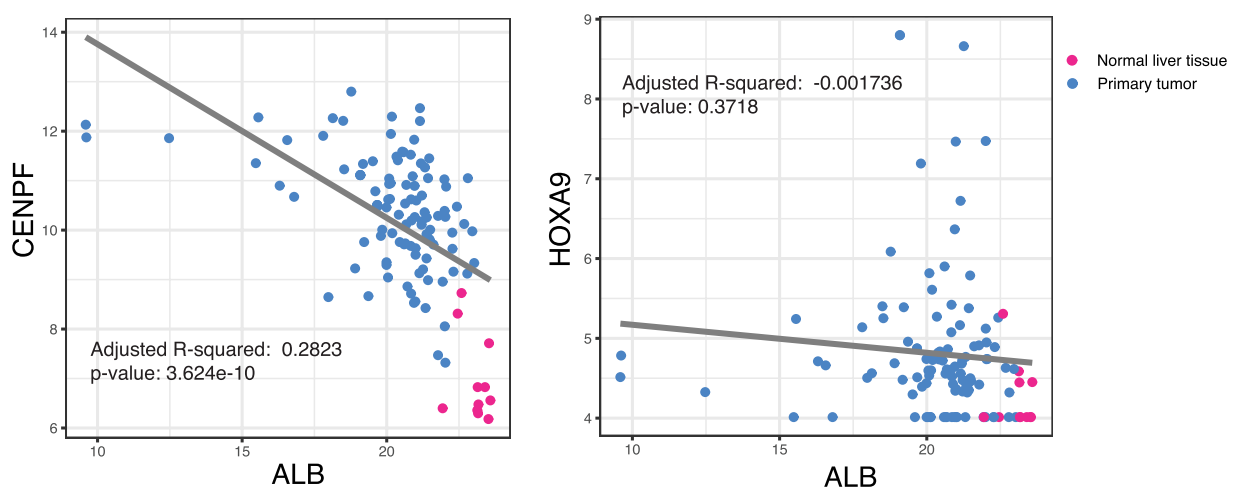

C
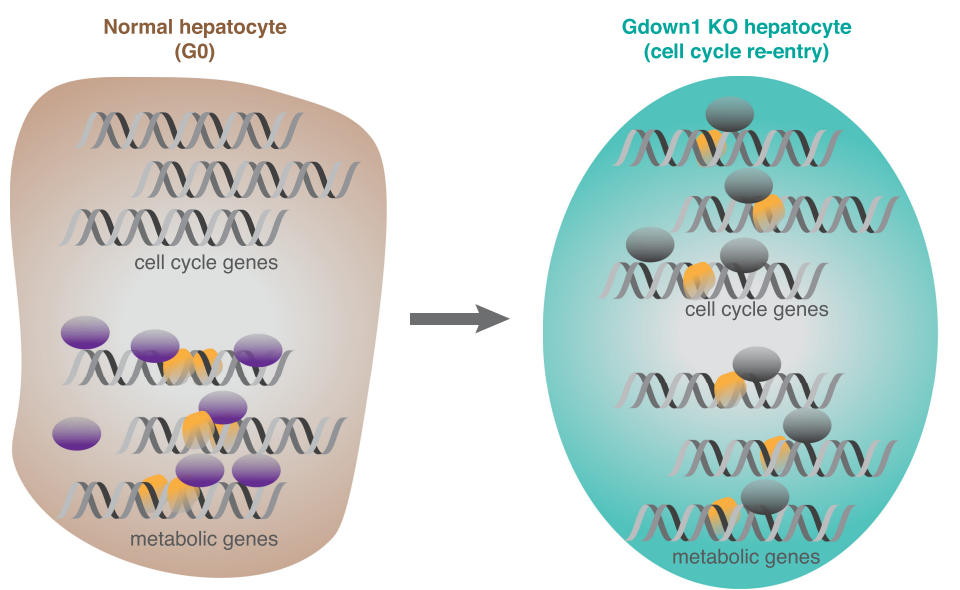

Figure 7. Expression of metabolic genes is inversely correlated with expression of cell cycle-related genes in HCC. $(A)$ Comparison of mRNA expression of cell cycle-related genes and highly expressed liver-specific genes in normal liver tissue or in HCC cohorts with high impact p53 mutations. (B) Scatter plot and regression line data for expression of $A L B$ and CENPF or HOXA9 in normal liver tissue (shown in pink) and in HCC cohorts with p53 mutations (shown in blue). (C) Schematic of Pol II recruitment to gene regions in the presence or absence of Gdown1. 
While p21 arrests the cell cycle by inhibiting cyclin-dependent kinases (CDKs), it also has oncogenic activities (Abbas and Dutta 2009). In this regard, the direct binding of $\mathrm{p} 21$ to cyclin D1 is one way to maintain the nuclear localization of cyclin D1, which promotes the assembly of cyclin D1/CDK4 or cyclin D1/CDK6 complexes without inhibiting the kinase activities (LaBaer et al. 1997; Alt et al. 2002). The observed cell cycle re-entry at $8 \mathrm{wk}$ might be explained by the p21 oncogenic activity; and the expression of proapoptotic genes activated by p53 could cause cell death. Although the exact mechanism that triggers activation of an apoptotic pathway remains unclear, the continuous expression of cyclin D1 may contribute to the driving of hepatocytes to cell death. Supporting this possibility, neuronal programmed cell death is accompanied by cyclin D1 induction, and overexpression of cyclin D1 causes apoptosis not only in neural cells but also in nonneural cells (Freeman et al. 1994; Kranenburg et al. 1996). Also, apart from a role in cell cycle progression, cyclin D1 has several additional functions, including the regulation of transcription factors (Musgrove et al. 2011; Pestell 2013), that might contribute to the observed apoptosis.

p53 is a tumor suppressor that is most frequently mutated in human cancers (Kastenhuber and Lowe 2017). The more severe phenotype of the double Gdown1;p53 KO $\left(\mathrm{DKO}^{A l b-c r e}\right)$ liver relative to the Gdown1 KO liver indicates a p53 protective role in the Gdown1 KO context. Although cell cycle regulators, such as cyclin A2 or cyclin B2, that are required for proper progression are all expressed in $\mathrm{DKO}^{A l b \text {-cre }}$ liver, the cell cycle is clearly dysregulated and generates incomplete mitoses. The mechanism underlying this dysregulation is unknown, although the up-regulated expression of mitotic genes might be involved. Thus, Aurora-A kinase overexpression, which is often observed in various cancers, leads to disruption of the cell cycle checkpoint as well as to aneuploidy (Marumoto et al. 2005). In this regard, Aurora-B, overexpression of which causes effects similar to those of Aurora-A (Willems et al. 2018), was also up-regulated in DKO ${ }^{\text {Alb-cre }}$ liver. Since Aurora kinases and p53 are mutually regulated (Sasai et al. 2016), the Aurora-B overexpression resulting from p53 loss could cause the cytokinesis failure observed in $\mathrm{DKO}^{\text {Alb-cre }}$ hepatocytes.

Apart from the histological evidence for dysplasia in $\mathrm{DKO}^{\text {Alb-cre }}$ liver, the associated RNA expression profile, including the up-regulation of cyclin D1, is similar to that of several types of hepatocellular carcinoma (HCC) suggesting the potential for premalignant transformation. Cyclin D1 amplification and overexpression are frequently observed in a wide variety of cancers (Musgrove et al. 2011). Also, transgenic mice that overexpress cyclin D1 in the liver develop hepatomegaly at $6 \mathrm{mo}$, which leads to the formation of adenomas or carcinomas (Deane et al. 2001). Considering the Gdown1 KO impact on gene expression, including the cyclin D1 overexpression that was further amplified by p53 ablation, the $\mathrm{DKO}^{\text {Alb-cre }}$ liver might be expected to develop tumors. Although we did not observe malignant transformation in $\mathrm{DKO}^{\text {Alb-cre }}$ liver at 6 mo of age, further analysis was prevented by a p53 KO- caused lymphoma that leads to death around 8 mo. Therefore, an alternative approach is necessary to examine this possibility.

In relation to direct transcription functions of Gdown1, in vitro studies have shown (1) an ability of Gdown1 to inhibit basal (activator- and Mediator-independent) transcription by preventing binding of initiation factors TFIIF and TFIIB to Pol II (Jishage et al. 2012), and (2) an ability of Mediator to reverse the transcriptional repressive capacity of Gdown1, rendering Pol II(G) particularly dependent on Mediator to initiate transcription $(\mathrm{Hu}$ et al. 2006). Thus, Pol II(G) may not be recruited to (or be active on) gene promoters on which Mediator/activator is not present, such that one key function of Gdown1 may be to restrict inappropriate Pol II recruitment and/or function on certain promoters in the absence of signal pathway-induced activators that recruit Mediator. In the liver, the majority of Gdown1 is found in association with Pol II as Pol II(G). Consistent with the mutually exclusive interaction of Gdown1 and TFIIF (or TFIIB) with Pol II, most of the Gdown1 is not observed either on promoters or at promoter proximal regions. Unexpectedly, however, Gdown1 was detected on the gene bodies of actively transcribed genes in the liver. This raises an important question as to how Gdown1 associates with Pol II during the various phases of the transcription cyclefrom Pol II recruitment to elongation. Our structural studies and in vitro transcription assays with purified factors (Hu et al. 2006; Jishage et al. 2012, 2018) suggested a model in which Mediator interaction with promoter-associated Pol II(G) destabilizes Gdown1 association with Pol II, and thus allows TFIIF and TFIIB binding to Pol II. Therefore, it is reasonable to speculate that full or partial dissociation of Gdown1 from Pol II (G) must occur for transcriptional activation (including initiation), which is generally Mediator-dependent in cells. However, our current results suggest that, at least for the highly active genes in hepatocytes, the Gdown1-Pol II interaction is maintained through the entire transcriptional cycle. One possibility is that the Gdown1-Pol II interaction is dynamic and reformed after Pol II initiation and promoter clearance. Consistent with this idea, biochemical assays on a model promoter have indicated an ability of Gdown1 to reassociate with Pol II after promoter clearance (DeLaney and Luse 2016). Future biochemical assays with purified factors on relevant genes, occupied by Pol II(G) in cells, should provide further information on the possible in vivo relevance of the conditional (Mediator-independent) inhibitory effect of Gdown1 on Pol II transcription in vitro. But regardless of this interesting issue, our current results have clearly demonstrated a strong positive transcription function of Gdown1 in association with elongating Pol II on the most actively transcribed liverspecific genes.

In relation to the Gdown1 postinitiation functions (including termination) indicated here, the specific mechanism of action of Gdown1 in association with elongating Pol II in gene bodies remains unclear. However, our previous study showed that Pol II(G) does not inhibit Pol II elongation in a purified in vitro assay system (Hu et al. 2006), 
while another study showed that Gdown1 can actually facilitate Pol II elongation in a less defined in vitro assay (Cheng et al. 2012).

Thus, a likely possibility for Gdown1 function in association with elongating Pol II on the liver-specific genes is a role in transcription elongation. Relevant to possible Pol II-associated Gdown1 interactions during elongation, a recent cryo-EM study described an activated Pol II elongation complex that includes DSIF, the PAF1 complex (PAF1C), and SPT6 (Vos et al. 2018); and superimposing the Pol II(G) cryo-EM structure (Jishage et al. 2018) on the elongation complex structure reveals no overlap with these elongation factors (except for LEO1 in PAF1C) in the static structure. However, it remains unknown whether Pol II-bound Gdown1 interacts directly with PAF1C (or other factors) in the elongation complex and how PAF1C regulates elongating Pol II in normal mouse liver. A further understanding of the function and mechanism of action of Gdown1 through interactions with elongating Pol II will necessitate further biochemical studies with more physiological (chromatin) templates where elongation factor functions are especially evident (Kim et al. 2010).

The loss of Gdown1 in the liver leads to substantial decreases in Pol II association with highly transcribed genes, resulting in the down-regulation of RNA expression. Notably, RNA transcripts of these Gdown1 targeted genes account for $\sim 30 \%$ of total liver transcripts. Therefore, the impact of the reduction of Pol II recruitment to these genes would not be insignificant for global gene expression. Notably, the Pol II recruitment to the albumin gene is immediately affected by Gdown1 KO. The albumin gene is the most highly expressed gene in the liver, and its transcriptional activation depends on an enhancer region that lies $\sim 10 \mathrm{~kb}$ upstream of the transcription start site (Pinkert et al. 1987) and closely resembles superenhancers. Superenhancers are extremely sensitive to perturbation of associated components (Hnisz et al. 2017), such that loss of Gdown1 might contribute to the prompt reduction of Pol II recruitment to the albumin gene.

There is an unambiguous inverse correlation between the expression of Gdown1 target genes and cell cycle-related genes. The down-regulated expression of highly activated genes in the liver leads to the immediate upregulation of genes encoding proteins involved in poly (A) binding, spliceosome function, and mitochondrion function, which are essential cellular components. The transcription of cyclin D1 also is activated in an unknown and apparently noncanonical manner. In normal liver, hepatocytes are committed to expressing highly selected genes that are involved in synthesis of plasma proteins or in metabolism. Thus, a disproportionate amount of Pol II is engaged in transcription of these genes. Although the exact mechanism leading to activation of cell cycle-related genes remains unclear, a reduction of Pol II recruitment to the liver-specific genes, as observed in the absence of Gdown1, could make Pol II available to other genes. Also, in the absence of Gdown1, which restricts Mediator/activator-independent transcription, Pol II recruitment could occur in a less competitive environment. Consequently, the expression of heavily Mediator/activa- tor-dependent genes would be decreased, while genes whose transcription is maintained at the basal level might be activated. This Pol II reallocation to other genes might underlie hepatocyte re-entry into the cell cycle (Fig. 7C).

The recent genomic characterization of HCCs has shown frequent mutations in metabolic genes that include $A L B, A P O B$, and CPS1 (Schulze et al. 2015; Fujimoto et al. 2016; The Cancer Genome Atlas Research Network 2017); and genomic alterations in $A L B$ may down-regulate $A L B$ expression (Fernandez-Banet et al. 2014). Previous studies also suggest that metabolic reprogramming plays a key role in the progression of hepatocytes to malignant HCC (The Cancer Genome Atlas Research Network 2017). However, the molecular mechanisms that contribute to the tumorigenesis have remained unknown. Our study provides important insights into a mechanism whereby down-regulation of highly expressed genes could contribute to induction of hepatocyte re-entry into the cell cycle, and thus has important implications both for hepatocarcinogenesis and for liver regeneration.

Materials and methods

Animals

Gdown $1^{\text {flox/flox }}$ mice were generated using a Gdown1 targeting vector (Supplemental Fig. S1A) that was obtained from the KOMP (the Trans-NIH Knock-Out Mouse Project) Repository. Gdown $1^{\text {flox/flox }}$ mice were maintained on a C57BL/6 background. Mice carrying a Gdown 1 knockout allele were generated by crossing Gdown $1^{\text {f/f }}$ mice with E2A-Cre transgenic mice (The Jackson Laboratory stock no. 003724). To conditionally delete Gdown1 in the liver, Gdown $1^{\text {flox/flox }}$ mice were crossed with transgenic mice expressing Cre under the control of the albumin promoter (Alb-Cre mice) (stock no. 003574, The Jackson Laboratory). To generate $p 53$ and Gdown1 double knockout (DKO $\left.{ }^{\text {Alb-cre }}\right)$ mice, $p 53^{-/-}$mice (The Jackson Laboratory 002101) were crossed with Gdown $1^{\text {flox/flox }}$ mice (p53KO) followed by crossing with $A 1 b$ Cre mice. To generate $\mathrm{DKO}^{\text {Alb-creERT2 }}$ mice, $p 53 \mathrm{KO}$ mice were crossed with transgenic mice carrying Alb-creERT2 (Schuler et al. 2004), which were a gift from Dr. Czaja (Albert Einstein College of Medicine, NY). For tamoxifen-inducible KO experiments, mice received a single intraperitoneal injection of $100 \mathrm{mg} / \mathrm{kg}$ tamoxifen. For acute injury experiments by carbon tetrachloride, mice received a single intraperitoneal injection of $1 \mathrm{~mL} / \mathrm{kg}$ carbon tetrachloride in corn oil or corn oil for control. Mice were sacrificed from 11:00 a.m. to 1:00 p.m. Mice were maintained under controlled environmental conditions under a 12-h light/dark cycle and allowed ad libitum access to water and standard laboratory diet. Both male and female mice were used for this study. All animal experiments were approved and performed in accordance with the Institutional Animal Care and Use Committee (IACUC) at Rockefeller University.

\section{Liver function tests}

Whole blood from mice was collected via retro-orbital puncture in $\mathrm{BD}$ Microtainer blood collection tubes and incubated for $30 \mathrm{~min}$ at room temperature, followed by centrifugation at $12,000 \mathrm{~g}$ for $2 \mathrm{~min}$. Alkaline phosphatase (ALP) and triglycerides (TRIG) were measured at the Department of Comparative Pathology in Memorial Sloan Kettering Cancer Center. 
Protein isolation and immunoblot

Liver tissues were homogenized in sucrose A buffer $(15 \mathrm{mM}$ Hepes at pH 7.9, $60 \mathrm{mM} \mathrm{KCl}, 2 \mathrm{mM}$ EDTA at $\mathrm{pH} 8.0,0.32 \mathrm{mM}$ sucrose) and layered onto sucrose B buffer (15 mM Hepes at $\mathrm{pH}$ 7.9, $60 \mathrm{mM} \mathrm{KCl}, 2 \mathrm{mM}$ EDTA at $\mathrm{pH} 8.0,30 \%$ sucrose), followed by centrifugation at $3000 \mathrm{rpm}$ for $15 \mathrm{~min}$. For whole-cell extracts, the pellet was resuspended in sucrose A buffer containing $0.2 \%$ Triton X-100 and layered onto sucrose B buffer. After centrifugation, the pellet was resuspended in urea/SDS loading buffer $(8 \mathrm{M}$ urea, $0.2 \mathrm{M}$ Tris- $\mathrm{HCl}$ at $\mathrm{pH} 6.8,1 \mathrm{mM}$ EDTA at $\mathrm{pH} 8.0,5 \%$ SDS, $1.5 \%$ DTT, $1 \%$ bromophenol blue) and incubated in a Thermomixer R (Eppendorf) for $0.5 \mathrm{~h}$ at $40^{\circ} \mathrm{C}$. For nuclear pellet analysis, the pellet was resuspended in $1 \times$ NUN buffer ( $1 \mathrm{M}$ urea, $20 \mathrm{mM}$ Hepes at $\mathrm{pH} 7.9,7.5 \mathrm{mM} \mathrm{MgCl} 2,0.2 \mathrm{mM}$ EDTA at $\mathrm{pH}$ $8.0,300 \mathrm{mM} \mathrm{NaCl}, 1 \% \mathrm{NP} 40,1 \mathrm{mM}$ DTT) and incubated with rotation for $5 \mathrm{~min}$ at $4^{\circ} \mathrm{C}$, followed by centrifugation at $1000 \mathrm{~g}$ for $3 \mathrm{~min}$. The pellet was resuspended in urea/SDS loading buffer and incubated in a Thermomixer R for $0.5 \mathrm{~h}$ at $40^{\circ} \mathrm{C}$. For Pol II purification, frozen liver tissues were homogenized in sucrose A buffer and layered onto sucrose B buffer, followed by centrifugation at $3000 \mathrm{rpm}$ for $15 \mathrm{~min}$. The pellet was resuspended in one pellet volume of $1 \times$ NUN buffer and incubated for $10 \mathrm{~min}$ on ice, followed by centrifugation at 13,000 rpm for $15 \mathrm{~min}$. The supernatant was dialyzed in TGEA buffer $(20 \mathrm{mM}$ Tris- $\mathrm{HCl}$ at $\mathrm{pH}$ 7.9 at $4{ }^{\circ} \mathrm{C}, 25 \%$ glycerol, $0.1 \mathrm{mM}$ EDTA at $\mathrm{pH}$ 8.0, $2 \mathrm{mM} \mathrm{DTT}$, $0.5 \mathrm{mM}$ PMSF, 0.1 M ammonium sulfate) and fractionated on a DEAE Sephacel column (GE Healthcare). The flowthrough fractions were further fractionated on a phosphocellulose 11 column. For immunoblot, the following antibodies were used: antiGdown1 (Jishage et al. 2012), anti-RPB3 (Bethyl Laboratories A303-771A), anti-cyclinD1 (Abcam ab16663), anti-p21 (Abcam ab188224), anti-phospho-STAT3 (Cell Signaling Technology 9145), anti-NF-кB p65 (Cell Signaling Technology 8242), anti- $\beta$ catenin (Abcam ab32572).

\section{Immunohistochemistry}

Tissues were fixed in $4 \%$ paraformaldehyde in phosphate-buffered saline (PBS) for $24 \mathrm{~h}$, and then processed for embedding in paraffin. Tissue sections $(5 \mu \mathrm{m})$ were cut and deparaffinized in xylene, followed by serial $(100 \%, 95 \%, 70 \%$, and $50 \%)$ alcohol washes to rehydrate, and were stained with hematoxylin and eosin (H\&E). The rehydrated sections were boiled in antigen unmasking solution (Table 1) (Vector Laboratories) in a pressure cooker for $15 \mathrm{~min}$. After blocking with $5 \%$ goat serum in PBS for $20 \mathrm{~min}$, primary antibodies in $5 \%$ goat serum and $0.1 \%$ Triton X-100 in PBS at the indicated dilutions (Table 1) were applied to the sections and were incubated overnight at $4^{\circ} \mathrm{C}$. The detection was performed us- ing VECTASTAIN Elite ABC HRP kit (Vector Laboratories) according to manufacturer's instructions and the sections were counterstained with hematoxylin. Tunel assays were performed as described previously (Gavrieli et al. 1992). For Sirius red staining, following deparaffinization, the sections were stained with Picro-Sirius red solution containing $0.1 \%$ Direct Red 80 (\#365548, Sigma) and 0.1\% fast green (F7252, Sigma) in $1.2 \%$ saturated aqueous picric acid solution (Sigma 197378) for $1 \mathrm{~h}$. Sections were rinsed with water, dehydrated, and mounted with Vecta Mount (Vector Laboratories).

\section{RNA isolation and RT-PCR}

Liver tissue samples were homogenized in $0.7 \mathrm{~mL}$ of TRIZOL (Thermo Fisher). RNA was purified by RNA Clean \& concentrator (Zymo research). RNA was reverse-transcribed using SuperScript III first strand synthesis kit (Invitrogen). Real-time PCR was performed on an Applied Biosystems 7300 real-time PCR system using QuantiTect SYBR Green mix. Changes in mRNA expression were calculated using the $\Delta \Delta \mathrm{Ct}$ method and are presented as fold-change in relation to expression of the $A c t b$ gene.

Microarray and RNA-seq analysis

RNA quality was assessed using an Agilent Bioanalyzer. Microarray analysis was performed using Affymetrix Gene Chip Gene 2.0 ST arrays according to the manufacturer's instructions. The data expressed as CEL files were normalized by the robust multiarray average method with the Expression Console software (Affymetrix). For RNA-seq, an RNA library was generated using SMARTer stranded total RNA sample preparation kits (Takara Bio) according to the manufacturer's instructions. Library quality was evaluated using the Bioanalyzer and sequenced on Illumina NextSeq High (75 bp single end). Reads were processed using Trimmomatic (version 0.39) (Bolger et al. 2014) and aligned to the mouse genome (mm10) using hisat2 (version 2.1.0) (Kim et al. 2015). Aligned reads were counted using featureCounts (Subread version 1.6.4) (Liao et al. 2014), and differential expression analysis was performed using DESeq2 (version 1.22.2) (Love et al. 2014). GO pathway analysis was performed by DAVID Bioinformatics Resources 6.8, and gene set enrichment analysis was performed by GSEA (Subramanian et al. 2005).

\section{ChIP-seq analysis}

Liver tissues were homogenized in sucrose A buffer $(15 \mathrm{mM}$ Hepes at pH7.9, $60 \mathrm{mM} \mathrm{KCl}, 2 \mathrm{mM}$ EDTA, $0.32 \mathrm{mM}$ sucrose)

Table 1. Primary antibodies

\begin{tabular}{llllll}
\hline Antibody & \multicolumn{1}{c}{ Source } & Identifier & Host animal & Dilution & Antigen retrieval \\
\hline Ki67 & Abcam & ab16667 & Rabbit & $1: 100$ & $\mathrm{pH} 6.0$ \\
CyclinD1 & Thermo & RM-9104-S1 & Rabbit & $1: 100$ & $\mathrm{pH} 6.0$ \\
SMA & Abcam & ab32575 & Rabbit & $1: 500$ & $\mathrm{pH} 6.0$ \\
KRT19 & DSHB & Troma-III & Rat & $1: 200$ & $\mathrm{pH} 9.0$ \\
Phospho-H3 & Abcam & ab5176 & Rabbit & $1: 2000$ & $\mathrm{pH} 6.0$ \\
Glutamine synthetase & Sigma & G2781 & Rabbit & $1: 40,000$ & $\mathrm{pH} 6.0$ \\
p21 & Abcam & ab188224 & Rabbit & $1: 1000$ & $\mathrm{pH} 6.0$ \\
p53 & Leica & NCL-L-P53-CM5p & Rabbit & $1: 800$ & $\mathrm{pH} 6.0$ \\
CD44 & Cell Signaling Technology & 37259 & Rabbit & $1: 500$ & $\mathrm{pH} 6.0$ \\
Phospho-c-Jun & Cell Signaling Technology & 3270 & Rabbit & $1: 200$ & $\mathrm{pH} 6.0$ \\
AFP & Biocare Medical & CP028A & Rabbit & $1: 100$ & $\mathrm{pH} 6.0$ \\
\hline
\end{tabular}


and layered onto sucrose B buffer (15 mM Hepes at pH 7.9, $60 \mathrm{mM}$ $\mathrm{KCl}, 2 \mathrm{mM}$ EDTA, $30 \%$ sucrose), followed by centrifugation at $3000 \mathrm{rpm}$ for $15 \mathrm{~min}$. The pellet was resuspended in sucrose A buffer containing $0.2 \%$ Triton X-100 and layered onto sucrose B buffer. After centrifugation, the pellet was resuspended in MNase buffer and incubated with MNase (New England Biolabs) for $10 \mathrm{~min}$ at $37^{\circ} \mathrm{C}$. The MNase-digested chromatin was further sonicated briefly and centrifuged at $14,000 \mathrm{rpm}$ for $15 \mathrm{~min}$. The supernatant was diluted in Buffer C (20 mM Hepes at $\mathrm{pH} 7.9$, $100 \mathrm{mM} \mathrm{KCl}, 2 \mathrm{mM}$ EDTA, $20 \%$ glycerol, $0.1 \% \mathrm{NP} 40$ ) and precleared with Dynabeads Protein A for $2 \mathrm{~h}$ at $4^{\circ} \mathrm{C}$. Anti-Gdown 1 antibodies (Jishage et al. 2012) or anti-RPB3 antibodies (Bethyl Laboratories A303-771A) that were preincubated with Dynabeads Protein A, were added to the precleared chromatin, followed by rotation overnight at $4^{\circ} \mathrm{C}$. The Dynabeads were washed three times in buffer $\mathrm{C}$ for $10 \mathrm{~min}$ and rinsed in TE buffer $(10 \mathrm{mM}$ Tris at $\mathrm{pH} 8,1 \mathrm{mM}$ EDTA), followed by two elutions in TE buffer containing $1 \%$ SDS for $15 \mathrm{~min}$ at $65^{\circ} \mathrm{C}$. The combined eluates were treated with $10 \mu \mathrm{g} / \mathrm{mL}$ RNase A followed by $0.1 \mathrm{mg} / \mathrm{mL}$ proteinase $\mathrm{K}$, and DNA was extracted by QIAquick PCR purification kits (Qiagen). DNA quality was assessed using an Agilent Bioanalyzer, and quantified using a Qubit Fluorometer (Invitrogen). ChIP-seq libraries were generated using DNA SMART ChIP-seq kits (Takara Bio) according to the manufacturer's instructions. The library quality was evaluated using the Bioanalyzer and sequenced on Illumina NextSeq High (75 bp single end). Reads were trimmed using Trimmomatic (version 0.39) (Bolger et al. $2014)$ and aligned to the mouse genome $(\mathrm{mm} 10)$ using Bowtie2 (version 2.3.5) (Langmead and Salzberg 2012), followed by process using Samtools (Li et al. 2009). Peak calling was performed using MACS2 (Zhang et al. 2008) for narrow peaks and HOMER (Heinz et al. 2010) for broad peaks (region), and region annotation was performed using HOMER. Aligned reads were normalized using deepTools (Ramírez et al. 2016) and visualized in the Wash U Epigenome Browser (Zhou and Wang 2012).

\section{Quantification and statistical analysis}

Unpaired two-tailed $t$ test was used to analyze differences between two groups. $P$-values less than 0.05 were considered statistically significant. The analysis was performed using GraphPad Prism8 (GraphPad software).

\section{Additional resources}

All raw data are deposited in GEO and the accession number is GSE144212.

\section{Acknowledgments}

We thank Sohail Malik and Alan Gerber for discussions and critical reading of the manuscript. This study was supported by National Institutes of Health grants R01 CA202245 and R01 CA129325 to R.G.R. K.I. was supported by T32 grant CA009673 from the National Cancer Institute and a postdoctoral fellowship from the Japan Society for the Promotion of Science. Author contributions: M.J. performed analyses for $\mathrm{KO}^{\text {Alb-cre }}$, $\mathrm{DKO}^{\text {Alb-cre }}$, and DKO ${ }^{\text {Alb-creERT2 }}$ liver by histology, biochemical analysis, and RNA expression analysis. K.I. assisted $\mathrm{KO}^{\text {Alb-cre }}$ liver analysis. C.-S.C. performed the ChIP-seq analysis. X.Y. assisted the early embryonic analysis. M.Y. designed and performed the screening of Gdown1 KO mESC. M.J. and R.G.R. wrote the manuscript with input from all coauthors.

\section{Reference}

Abbas T, Dutta A. 2009. p21 in cancer: intricate networks and multiple activities. Nat Rev Cancer 9: 400-414. doi:10.1038/ $\operatorname{nrc} 2657$

Acevedo LG, Bieda M, Green R, Farnham PJ. 2008. Analysis of the mechanisms mediating tumor-specific changes in gene expression in human liver tumors. Cancer Res 68: 2641-2651. doi:10.1158/0008-5472.CAN-07-5590

Alt JR, Gladden AB, Diehl JA. 2002. p2 ${ }^{\text {Cip } 1}$ Promotes cyclin D1 nuclear accumulation via direct inhibition of nuclear export. J Biol Chem 277: 8517-8523. doi:10.1074/jbc.M108867200

Alvaro D, Mancino MG, Glaser S, Gaudio E, Marzioni M, Francis H, Alpini G. 2007. Proliferating cholangiocytes: a neuroendocrine compartment in the diseased liver. Gastroenterology 132: 415-431. doi:10.1053/j.gastro.2006.07.023

Bolger AM, Lohse M, Usadel B. 2014. Trimmomatic: a flexible trimmer for Illumina sequence data. Bioinformatics 30: 2114-2120. doi:10.1093/bioinformatics/btu170

Borlak J, Meier T, Halter R, Spanel R, Spanel-Borowski K. 2005. Epidermal growth factor-induced hepatocellular carcinoma: gene expression profiles in precursor lesions, early stage and solitary tumours. Oncogene 24: 1809-1819. doi:10.1038/si .onc. 1208196

Cairo S, Armengol C, De Reyniès A, Wei Y, Thomas E, Renard CA, Goga A, Balakrishnan A, Semeraro M, Gresh L, et al. 2008 . Hepatic stem-like phenotype and interplay of $\mathrm{Wnt} / \beta$ Catenin and Myc signaling in aggressive childhood liver cancer. Cancer Cell 14: 471-484. doi:10.1016/j.ccr.2008.11.002

Caldez MJ, Van Hul N, Koh HWL, Teo XQ, Fan JJ, Tan PY, Dewhurst MR, Too PG, Talib SZA, Chiang BE, et al. 2018. Metabolic remodeling during liver regeneration. Dev Cell 47: 425-438.e5. doi:10.1016/j.devcel.2018.09.020

The Cancer Genome Atlas Research Network. 2017. Comprehensive and integrative genomic characterization of hepatocellular carcinoma. Cell 169: 1327-1341.e23. doi:10.1016/j .cell.2017.05.046

Cheng B, Li T, Rahl PB, Adamson TE, Loudas NB, Guo J, Varzavand K, Cooper JJ, Hu X, Gnatt A, et al. 2012. Functional association of Gdown1 with RNA polymerase II poised on human genes. Mol Cell 45: 38-50. doi:10.1016/j.molcel.2011.10.022

Dai Y, Liu L, Zeng T, Zhu YH, Li J, Chen L, Li Y, Yuan YF, Ma S, Guan XY. 2013. Characterization of the oncogenic function of centromere protein $\mathrm{F}$ in hepatocellular carcinoma. Biochem Biophys Res Commun 436: 711-718. doi:10.1016/j.bbrc.2013 .06 .021

Deane NG, Parker MA, Aramandla R, Diehl L, Lee WJ, Washington MK, Nanney LB, Shyr Y, Beauchamp RD. 2001. Hepatocellular carcinoma results from chronic cyclin D1 overexpression in transgenic mice. Cancer Res 61: 5389-5395.

DeLaney E, Luse DS. 2016. Gdown1 associates efficiently with RNA polymerase II after promoter clearance and displaces TFIIF during transcript elongation. PLoS One 11: e0163649. doi:10.1371/journal.pone.0163649

Fausto N, Campbell JS, Riehle KJ. 2006. Liver regeneration. Hepatology 43: S45-S53. doi:10.1002/hep.20969

Fernandez-Banet J, Lee NP, Chan KT, Gao H, Liu X, Sung WK, Tan W, Fan ST, Poon RT, Li S, et al. 2014. Decoding complex patterns of genomic rearrangement in hepatocellular carcinoma. Genomics 103: 189-203. doi:10.1016/j.ygeno.2014.01.003

Fischer M. 2017. Census and evaluation of p53 target genes. Oncogene 36: 3943-3956. doi:10.1038/onc.2016.502

Freeman RS, Estus S, Johnson EM. 1994. Analysis of cell cycle-related gene-expression in postmitotic neurons-selective 
induction of cyclin D1 during programmed cell-death. Neuron 12: 343-355. doi:10.1016/0896-6273(94)90276-3

Fujimoto A, Furuta M, Totoki Y, Tsunoda T, Kato M, Shiraishi Y, Tanaka H, Taniguchi H, Kawakami Y, Ueno M, et al. 2016. Whole-genome mutational landscape and characterization of noncoding and structural mutations in liver cancer. Nat Genet 48: 500-509. doi:10.1038/ng.3547

Gavrieli Y, Sherman Y, Ben-Sasson SA. 1992. Identification of programmed cell death in situ via specific labeling of nuclear DNA fragmentation. J Cell Biol 119: 493-501. doi:10.1083/jcb .119 .3 .493

Heinz S, Benner C, Spann N, Bertolino E, Lin YC, Laslo P, Cheng JX, Murre C, Singh H, Glass CK. 2010. Simple combinations of lineage-determining transcription factors prime cis-regulatory elements required for macrophage and B cell identities. Mol Cell 38: 576-589. doi:10.1016/j.molcel.2010.05.004

Hirota K, Fukamizu A. 2010. Transcriptional regulation of energy metabolism in the liver. I Recept Signal Transduct Res 30: 403-409. doi:10.3109/10799893.2010.509730

Hnisz D, Shrinivas K, Young RA, Chakraborty AK, Sharp PA. 2017. A phase separation model for transcriptional control. Cell 169: 13-23. doi:10.1016/j.cell.2017.02.007

Hoshida Y, Nijman SM, Kobayashi M, Chan JA, Brunet JP, Chiang DY, Villanueva A, Newell P, Ikeda K, Hashimoto M, et al. 2009. Integrative transcriptome analysis reveals common molecular subclasses of human hepatocellular carcinoma. Cancer Res 69: 7385-7392. doi:10.1158/0008-5472.CAN-09-1089

Hu X, Malik S, Negroiu CC, Hubbard K, Velalar CN, Hampton B, Grosu D, Catalano J, Roeder RG, Gnatt A. 2006. A mediatorresponsive form of metazoan RNA polymerase II. Proc Natl Acad Sci 103: 9506-9511. doi:10.1073/pnas.0603702103

Huang J, Rudnick DA. 2014. Elucidating the metabolic regulation of liver regeneration. Am J Pathol 184: 309-321. doi:10.1016/j .ajpath.2013.04.034

Jishage M, Malik S, Wagner U, Uberheide B, Ishihama Y, Hu X, Chait BT, Gnatt A, Ren B, Roeder RG. 2012. Transcriptional regulation by $\mathrm{Pol} \mathrm{II}(\mathrm{G})$ involving mediator and competitive interactions of Gdown 1 and TFIIF with Pol II. Mol Cell 45: 5163. doi:10.1016/j.molcel.2011.12.014

Jishage M, Yu X, Shi Y, Ganesan SI, Chen WY, Sali A, Chait BT, Asturias FJ, Roeder RG. 2018. Architecture of Pol II $(\mathrm{G})$ and molecular mechanism of transcription regulation by Gdown1. Nat Struct Mol Biol 25: 859-867. doi:10.1038/s41594-0180118-5

Kastenhuber ER, Lowe SW. 2017. Putting p53 in context. Cell 170: 1062-1078. doi:10.1016/j.cell.2017.08.028

Kim J, Guermah M, Roeder RG. 2010. The human PAF1 complex acts in chromatin transcription elongation both independently and cooperatively with SII/TFIIS. Cell 140: 491-503. doi:10 $.1016 /$ j.cell.2009.12.050

Kim D, Langmead B, Salzberg SL. 2015. HISAT: a fast spliced aligner with low memory requirements. Nat Methods 12: 357-360. doi:10.1038/nmeth.3317

Klein EA, Assoian RK. 2008. Transcriptional regulation of the cyclin D1 gene at a glance. J Cell Sci 121: 3853-3857. doi:10 $.1242 /$ jcs.039131

Kranenburg O, vanderEb A, Zantema A. 1996. Cyclin D1 is an essential mediator of apoptotic neuronal cell death. Embo Journal 15: 46-54. doi:10.1002/j.1460-2075.1996.tb00332.x

Kurinna S, Barton MC. 2011. Cascades of transcription regulation during liver regeneration. Int J Biochem Cell Biol 43: 189-197. doi:10.1016/j.biocel.2010.03.013

LaBaer J, Garrett MD, Stevenson LF, Slingerland JM, Sandhu C, Chou HS, Fattaey A, Harlow E. 1997. New functional activi- ties for the p21 family of CDK inhibitors. Genes Dev 11: 847-862. doi:10.1101/gad.11.7.847

Langmead B, Salzberg SL. 2012. Fast gapped-read alignment with Bowtie 2. Nat Methods 9: 357-359. doi:10.1038/nmeth.1923

Lee JS, Chu IS, Mikaelyan A, Calvisi DF, Heo J, Reddy JK, Thorgeirsson SS. 2004. Application of comparative functional genomics to identify best-fit mouse models to study human cancer. Nat Genet 36: 1306-1311. doi:10.1038/ng1481

Li H, Handsaker B, Wysoker A, Fennell T, Ruan J, Homer N, Marth G, Abecasis G, Durbin R. Genome Project Data Processing S. 2009. The sequence alignment/Map format and SAMtools. Bioinformatics 25: 2078-2079. doi:10.1093/bioin formatics/btp352

Liao H, Winkfein RJ, Mack G, Rattner JB, Yen TJ. 1995. CENP-F is a protein of the nuclear matrix that assembles onto kinetochores at late G2 and is rapidly degraded after mitosis. J Cell Biol 130: 507-518. doi:10.1083/jcb.130.3.507

Liao Y, Smyth GK, Shi W. 2014. featureCounts: an efficient general purpose program for assigning sequence reads to genomic features. Bioinformatics 30: 923-930. doi:10.1093/bioinfor matics/btt656

Liu XL, Kraus WL, Bai XY. 2015. Ready, pause, go: regulation of RNA polymerase II pausing and release by cellular signaling pathways. Trends Biochem Sci 40: 516-525. doi:10.1016/j .tibs.2015.07.003

Love MI, Huber W, Anders S. 2014. Moderated estimation of fold change and dispersion for RNA-seq data with DESeq2. Genome Biol 15: 550. doi:10.1186/s13059-014-0550-8

Malik S, Roeder RG. 2010. The metazoan Mediator co-activator complex as an integrative hub for transcriptional regulation. Nat Rev Genet 11: 761-772. doi:10.1038/nrg2901

Marumoto T, Zhang D, Saya H. 2005. Aurora-A—a guardian of poles. Nat Rev Cancer 5: 42-50. doi:10.1038/nrc1526

Michalopoulos GK. 2007. Liver regeneration. J Cell Physiol 213: 286-300. doi:10.1002/jcp.21172

Michalopoulos GK. 2014. Advances in liver regeneration. Expert Rev Gastroenterol Hepatol 8: 897-907. doi:10.1586/17474124 .2014 .934358

Michalopoulos GK. 2017. Hepatostat: liver regeneration and normal liver tissue maintenance. Hepatology 65: 1384-1392. doi:10.1002/hep. 28988

Mohn KL, Laz TM, Melby AE, Taub R. 1990. Immediate-early gene expression differs between regenerating liver, insulinstimulated H-35 cells, and mitogen-stimulated Balb/c 3T3 cells. Liver-specific induction patterns of gene 33, phosphoenolpyruvate carboxykinase, and the jun, fos, and egr families. I Biol Chem 265: 21914-21921.

Mullany LK, White P, Hanse EA, Nelsen CJ, Goggin MM, Mullany JE, Anttila CK, Greenbaum LE, Kaestner KH, Albrecht JH. 2008. Distinct proliferative and transcriptional effects of the D-type cyclins in vivo. Cell Cycle 7: 2215-2224. doi:10 $.4161 /$ cc.7.14.6274

Musgrove EA, Caldon CE, Barraclough J, Stone A, Sutherland RL. 2011. Cyclin D as a therapeutic target in cancer. Nat Rev Cancer 11: 558-572. doi:10.1038/nrc3090

Nelsen CJ, Rickheim DG, Timchenko NA, Stanley MW, Albrecht JH. 2001. Transient expression of cyclin D1 is sufficient to promote hepatocyte replication and liver growth in vivo. Cancer Res 61: 8564-8568.

Paranjpe S, Bowen WC, Mars WM, Orr A, Haynes MM, DeFrances MC, Liu S, Tseng GC, Tsagianni A, Michalopoulos GK. 2016. Combined systemic elimination of MET and epidermal growth factor receptor signaling completely abolishes liver regeneration and leads to liver decompensation. Hepatology 64: 1711-1724. doi:10.1002/hep.28721 
Pestell RG. 2013. New roles of cyclin D1. Am J Pathol 183: 3-9. doi:10.1016/j.ajpath.2013.03.001

Pinkert CA, Ornitz DM, Brinster RL, Palmiter RD. 1987. An albumin enhancer located $10 \mathrm{~kb}$ upstream functions along with its promoter to direct efficient, liver-specific expression in transgenic mice. Genes Dev 1: 268-276. doi:10.1101/gad .1 .3 .268

Ramírez F, Ryan DP, Grüning B, Bhardwaj V, Kilpert F, Richter AS, Heyne S, Dündar F, Manke T. 2016. deepTools2: a next generation web server for deep-sequencing data analysis. Nucleic Acids Res 44: W160-W165. doi:10.1093/nar/ gkw257

Roeder RG. 2019. 50+ years of eukaryotic transcription: an expanding universe of factors and mechanisms. Nat Struct Mol Biol 26: 783-791. doi:10.1038/s41594-019-0287-x

Roginski RS, Mohan Raj BK, Birditt B, Rowen L. 2004. The human GRINL1A gene defines a complex transcription unit, an unusual form of gene organization in eukaryotes. Genomics 84: 265-276. doi:10.1016/j.ygeno.2004.04.004

Sasai K, Treekitkarnmongkol W, Kai K, Katayama H, Sen S. 2016. Functional significance of Aurora Kinases-p53 protein family interactions in cancer. Front Oncol 6: 247. doi:10.3389/fonc .2016 .00247

Schuler M, Dierich A, Chambon P, Metzger D. 2004. Efficient temporally controlled targeted somatic mutagenesis in hepatocytes of the mouse. Genesis 39: 167-172. doi:10.1002/gene .20039

Schulze K, Imbeaud S, Letouzé E, Alexandrov LB, Calderaro J, Rebouissou S, Couchy G, Meiller C, Shinde J, Soysouvanh F, et al. 2015. Exome sequencing of hepatocellular carcinomas identifies new mutational signatures and potential therapeutic targets. Nat Genet 47: 505-511. doi:10.1038/ng .3252

Subramanian A, Tamayo P, Mootha VK, Mukherjee S, Ebert BL, Gillette MA, Paulovich A, Pomeroy SL, Golub TR, Lander ES, et al. 2005. Gene set enrichment analysis: a knowledge- based approach for interpreting genome-wide expression profiles. Proc Natl Acad Sci 102: 15545-15550. doi:10.1073/ pnas.0506580102

Taub R. 2004. Liver regeneration: from myth to mechanism. Nat Rev Mol Cell Bio 5: 836-847. doi:10.1038/nrm1489

Thompson NL, Mead JE, Braun L, Goyette M, Shank PR, Fausto N. 1986. Sequential protooncogene expression during rat liver regeneration. Cancer Res 46: 3111-3117.

Villanueva A, Hoshida Y, Battiston C, Tovar V, Sia D, Alsinet C, Cornella H, Liberzon A, Kobayashi M, Kumada H, et al. 2011. Combining clinical, pathology, and gene expression data to predict recurrence of hepatocellular carcinoma. Gastroenterology 140: 1501-1512.e2. doi:10.1053/j.gastro.2011.02.006

Vos SM, Farnung L, Boehning M, Wigge C, Linden A, Urlaub H, Cramer P. 2018. Structure of activated transcription complex Pol II-DSIF-PAF-SPT6. Nature 560: 607-612. doi:10.1038/ s41586-018-0440-4

Willems E, Dedobbeleer M, Digregorio M, Lombard A, Lumapat PN, Rogister B. 2018. The functional diversity of Aurora kinases: a comprehensive review. Cell Div 13: 7. doi:10.1186/ s13008-018-0040-6

Witzel II, Koh LF, Perkins ND. 2010. Regulation of cyclin D1 gene expression. Biochem Soc Trans 38: 217-222. doi:10.1042/ BST0380217

Yin C, Evason KJ, Asahina K, Stainier DY. 2013. Hepatic stellate cells in liver development, regeneration, and cancer. J Clin Invest 123: 1902-1910. doi:10.1172/JCI66369

Zhang Y, Liu T, Meyer CA, Eeckhoute J, Johnson DS, Bernstein BE, Nusbaum C, Myers RM, Brown M, Li W, et al. 2008. Model-based analysis of ChIP-seq (MACS). Genome Biol 9: R137. doi:10.1186/gb-2008-9-9-r137

Zhou X, Wang T. 2012. Using the Wash U Epigenome Browser to examine genome-wide sequencing data. Curr Protoc Bioinformatics 40: 10.10.1-10.10.14. doi:10.1002/0471250953 .bi1010s40 


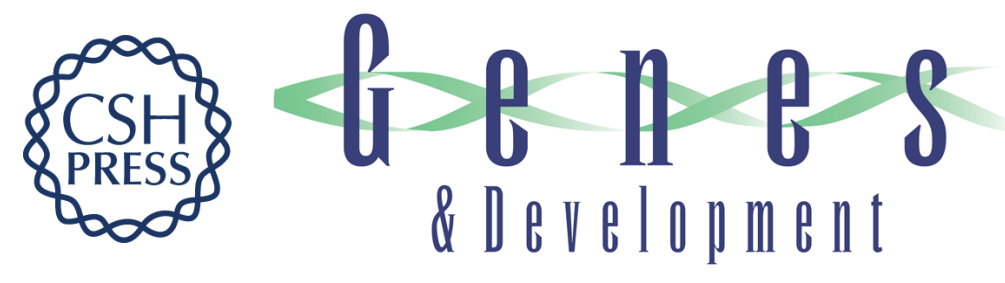

\section{Transcriptional down-regulation of metabolic genes by Gdown1 ablation induces quiescent cell re-entry into the cell cycle}

Miki Jishage, Keiichi Ito, Chi-Shuen Chu, et al.

Genes Dev. 2020, 34: originally published online May 7, 2020

Access the most recent version at doi:10.1101/gad.337683.120

\section{Supplemental http://genesdev.cshlp.org/content/suppl/2020/05/06/gad.337683.120.DC1 Material}

References This article cites 69 articles, 15 of which can be accessed free at: http://genesdev.cshlp.org/content/34/11-12/767.full.html\#ref-list-1

Creative This article is distributed exclusively by Cold Spring Harbor Laboratory Press for the first Commons six months after the full-issue publication date (see

License http://genesdev.cshlp.org/site/misc/terms.xhtml). After six months, it is available under a Creative Commons License (Attribution-NonCommercial 4.0 International), as described at http://creativecommons.org/licenses/by-nc/4.0/.

Email Alerting Receive free email alerts when new articles cite this article - sign up in the box at the top Service right corner of the article or click here.

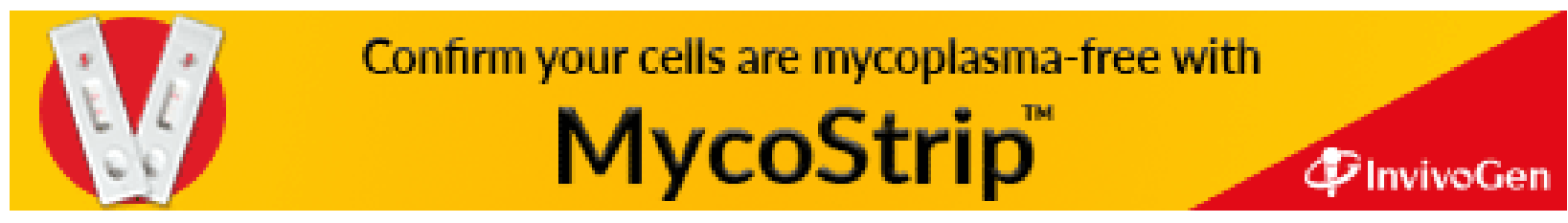

